Document downloaded from:

http://hdl.handle.net/10251/112515

This paper must be cited as:

Salas, J.; Yepes, V. (2018). Urban vulnerability assessment: Advances from the strategic planning outlook. Journal of Cleaner Production. 179:544-558.

doi:10.1016/j.jclepro.2018.01.088

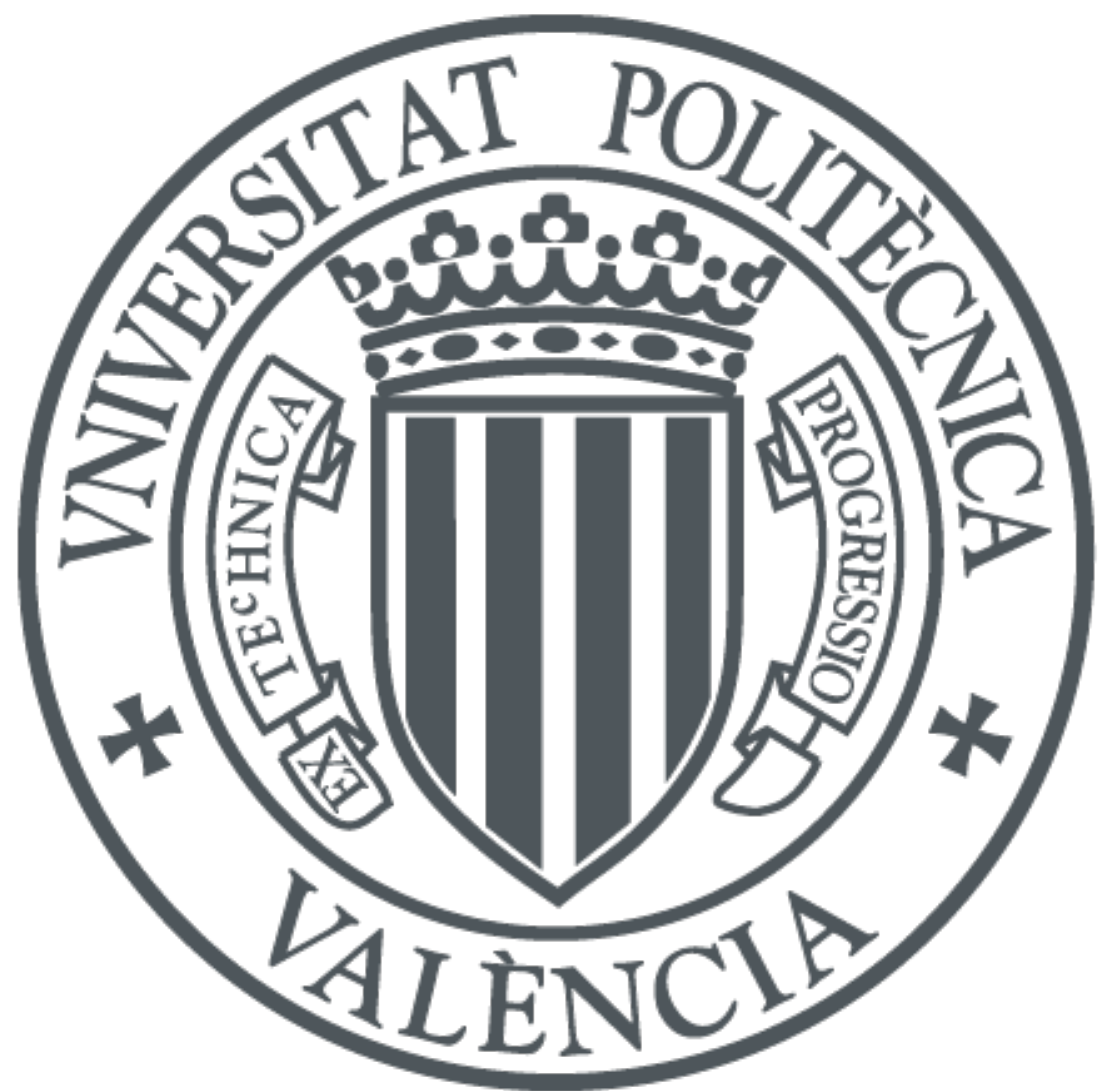

The final publication is available at

https://doi.org/10.1016/j.jclepro.2018.01.088

Copyright Elsevier

Additional Information 


\title{
Urban vulnerability assessment: Advances from the strategic
}

\section{planning outlook}

\author{
Jorge Salas ${ }^{1}$ \\ Víctor Yepes ${ }^{2}$
}

\begin{abstract}
Urban strategic planning and urban vulnerability assessment have increasingly become important issues in both policy agenda and academia. However, a comprehensive review of the advances made in urban vulnerability, emphasizing their shared aspects, has yet to be performed. The aiming of this paper is to addresses the latter by conducting an evaluation on assessment methods disclosed in this decade. Once their common evolutive pathway is traced, the review follows an analytical framework, based on the above, evaluating the research requirements from both a quantitative and qualitative point of view. Our findings indicate that the robustness, cognitive and participatory research lines are those in which most advancement has been made, while those of urban dynamics and multi-scale progressed the least. Our analysis also demonstrates that methods integrating more lines of research, as well as the employment of comprehensive approaches, promotes advancing the developmental stage. We conclude that the focusing of research lines should be shifted, in order to bridge the qualitative gap identified without demanding an improbable, quantitative increase.
\end{abstract}

Keywords: urban vulnerability, urban strategic planning, vulnerability assessment, current trend.

\footnotetext{
${ }^{1}$ Graduate Research Assistant, School of Civil Engineering, Universitat Politècnica de València, 46022 Valencia, Spain. Corresponding author. Phone +34963879563; fax: +34963877569; e-mail: jorsaher@doctor.upv.es

${ }^{2}$ Professor, ICITECH, Universitat Politècnica de València, 46022 Valencia, Spain. Phone +34963879563 ; fax: +34963877569; e-mail: vyepesp@cst.upv.es 


\section{Introduction}

Urban vulnerability (UV) in general, and its adaptive component in particular, have become key issue for urban strategic planning (USP) (Rigillo \& Cervelli, 2014; Nahiduzzaman et al., 2015), and for coping with climate change (McCarthy, 2001; Turner et al., 2003; Adger, 2006; Füssel, 2007; Birkmann et al., 2014; Chang \& Huang, 2015). Therefore, vulnerability assessments are increasingly being used by governments around the world (Fekete, 2009) for the purpose of strategic planning. This latter can be defined broadly as an effort to develop fundamental decisions and actions that shape and guide what an organizations, what it does and why it does it (Bryson et al., 2004). On the other hand, USP is a way of urban planning that is based on strategic planning, which foundations have evolved from the Control and Optimization paradigm, to the Discursive approach (Malekpour et al., 2015).

Regarding vulnerability, its most accepted definition (to climate change) is provided by the IPCC Assessment Report (McCarthy, K.S., \& (eds), 2001) as follows: "The degree to which a system (entity) is susceptible to, or unable to cope with, adverse effects of climate change, including climate variability and extremes. Vulnerability is a function of the character, magnitude, and rate of climate variation to which a system is exposed, its sensitivity, and its adaptive capacity". Nevertheless, there are many other definitions that challenge current thinking, to the extent that it is necessary to perform research specifically aimed at conceptual clarification (Füssel \& Klein, 2006; Wolf et al., 2013), which exceeds the scope of this study. A few aspects, however, are beyond question, one being the research requirements set in studies related to the assessment of this concept. Since urban vulnerability is a particularization of the general vulnerability concept, the entity being an urban framework, they share the aforementioned research lines (Romero Lankao \& Qin, 2011), which are close to those of USP. Thus by determining which attributes makes USP, which has a relatively long history, effective and then comparing 
that to recent Urban Vulnerability assessments (UVA) methods, it can be determined which of these requirements are missing in UVAs, and consequently appraise the advancement made on this field.

Accordingly, the questions that necessarily arise are what attributes characterize current USP research, and to what extent are them being followed by UVA research. Likewise, it is important to ascertain whether we can improve the existing progression, and if so, how. To respond these questions, a detailed review of the UVA area in the light of a comparative between USP and UVA evolutions, is needed. Thus, the scope of this work is shaped by urban vulnerability assessment methods disclosed from 2010 onwards, whose entity (system) is an urban framework. For the gathering of these methods, we employed a four-step process in which, by means of a general search, a forward search, a brief review and a content analysis, we systematically proceeded from studies regarding urban vulnerability in general to those presenting new UVA methods. By following those steps, this paper traces the evolutionary pathway, common for USP and UVA (Section 2) to develop, on this basis, an analytical framework (Section 3), which is applied to a sample of UVA methods (Section 4) in order to establish current advances and trends. The results reveal (Section 5) current research preferences, relations with other aspects such as schools of thought, stimuli or developmental stage, and inner synergies, all of which will allow for a desirable, plausible future to be envisaged, and insights for its achievement (Section 6). The paper concludes (Section 7) that the infrastructure-related stimuli are the most promising, and that a shift in focus towards the integration of cognitive, multi-objective, multiscale and dynamic research requirements would benefit the advance of urban vulnerability research.

\section{Evolution}

There has been a major evolution in the development of both USP and vulnerability assessment methods, which enable a common underlying pattern to be inferred. This 
similarity is made evident by introducing and comparing USP and UVA evolutions and research lines.

\subsection{Strategic planning}

On the one hand, as far as USP is concerned, its importance and goals have evolved from simple prediction models playing a minor role in post-WWII economic stabilization, to a protagonist one as a potential tool to assist the decision-making processes undertaken by today's urban planners. This process takes place by fostering the incorporation of those existing uncertainties and complexities in reality, changing from formulaic processes to discursive practices, and by the involvement of key stakeholders. The stages, in which the main objective was to maximize the available resources, or minimize the negative impact of the decisions, have given way to a new one recognizing the effect of uncertainty upon results, its unpredictability and the necessity of providing solutions that may help to meet changing circumstances (Malekpour et al., 2015).

Broadly speaking, three stages can be identified in this evolution: the first in which strategic planning served to make predictions and take decisions accordingly (predictand-act). The second, in which not only were predictions made but also several possible future scenarios were contemplated, and further criteria on managing available resources were established. The third stage, in which it is accepted that any predicted future will change and only broad directions of this change, as well as criteria to adapt to the coming circumstances, can be given. Malekpour et al. (2015) have called these three stages incremental, managerial and discursive; and incremental, modeling- managerial and discursive by Dominguez et al. (2011).

\subsection{Vulnerability assessment}

On the other hand, as far as vulnerability is concerned, its conceptual framework and lines of future research have evolved in a similar way: from the initial prediction, based on simplified models assessing impacts, to the current conceptualization. In the latter not 
only the impacts, but also the entity's capacity to improve its ability to anticipate hazards, to address them, and to overcome their consequences, are taken into account (Kaźmierczak \& Cavan, 2011). All this is accomplished by incorporating the uncertainty and complexity inherent in the real world (Munda, 2004; Füssel \& Klein, 2006) and by taking into account both the dynamic nature and the subjective side of vulnerability (Adger, 2006; Liu et al., 2010; King \& Blackmore, 2013; Pamungkas et al., 2014; Birkmann, et al., 2014). The initial and the current developmental stages have been referred to, respectively, as the preparation and the adaptation stages by Adger (2006), and as the impact assessment and the adaptation policy by Füssel et al. (2006). Between them, an intermediate development stage was also identified, in which not only was an impact assessment provided, but also an evaluation of the entity's adaptability. These developmental stages are put into a correlation in Table 1, which portrays how the methods have evolved. Regarding the time horizon considered, they changed from exclusively considering long-term planning (Füssel, 2003), to the establishment of the mid-to-long-term potential consequences of climate variability (National Assessment Synthesis Team, 2001), and on to providing assessments in the long and short term by allowing evaluations at different time slices (Harrison et al., 2015). Likewise, these examples illustrate how the consideration of adaptation has changed. In the first example, the assessment relies only on biophysical indicators without taking into account other aspects, such as socio-economic or socio-political aspects, related with the communities' adaptive capacity, which in contrast are taken into account in the other examples, and can lead to adaptive strategies. As to the incorporation of uncertainty, its treatment has ranged from its partial consideration, in the first case, by applying climate projections from different general circulation models, to a more extensive incorporation by investigating, in the other two cases, its effect on climate models by comparing the outcomes produced by different scenarios. These latter, in the case of the studies pertaining to the vulnerability and adaptation stages, were identified with the help of the involvement of 
the stakeholders, in contrast with the impact tool, which made no use of any kind of participatory process. In line with the evolution of stakeholder involvement, the analytical approaches employed have varied from the normative approach used in the adaptation stage example, in which the stakeholders themselves build the scenarios determining the models' outcomes, to the positive, found in studies representing the vulnerability and impact stages. In these latter, the role of stakeholders was only to help the scientists understand their needs, which drove a more linear and less policy-driven assessment. As to the understanding of the complex nature of vulnerability, the examples provided portray how they have changed from a biophysical model (reducing it to a single dimension), to a comprehensive one enabling a better understanding of complex crosssectoral and multi-scale interactions.

\subsection{Common research lines}

These similarities between USP and UVA can also be found in their current challenges and consequent research directions (Table 2). According to several authors, for the present, dealing with uncertainty is a major challenge for USP (de Graaf \& Dewulf, 2010; Malekpour et al., 2015); In addition, dealing with conflict, multiple valuation criteria or multiple alternatives as well as citizen involvement in the planning process are challenges for strategic urban planning, and have become major concerns. For the accomplishment of each purpose, several requirements are needed. Therefore, increasing the assessment robustness was pointed out as a proper method for facing uncertainty (Malekpour et al., 2015). Strategic capacity also referred to as strategic ambiguity, can deal, through the use of (for example) multi-objective optimization (MOO) approaches, with conflicts and multiple objectives (Giezen et al., 2015). This is achieved by means of MOO compromise solutions, which are able, unlike multi-criteria analysis, to deal with multiple dimensions, even when they are in conflict with each other (Munda, 2004). The incorporation of the social point of view and its preferences, subjective as they 
are, is what ultimately could be provided by the required social learning and participatory process (Malekpour et al., 2015; 2016; Zamarrón-Mieza et al., 2017).

Cognitive approaches have become relevant for the purpose of providing insights and to ease the extraction of relevant information, and should be present in USP, since it must be designed as a learning process, aiming to build a consensus in which different actors are considered (Wiechmann, 2008). On the other hand, the current USP trend focuses on the planning process itself rather than only on its results, and a cognitive approach empowers this feature (Yepes et al., 2015; Torres-Machi et al., 2017). Thus, cognitive approaches ease planners and decision-makers to grasp the underlying cause-effect relations, which are a requirement for UVA (Adger, 2006). Furthermore, facing multiple objectives makes explicit the trade-offs between them, contributing to their balance and thus reinforcing the value added by discursive strategies.

From the urban vulnerability point of view, current research directions have also been highlighted, and several requirements were outlined, such as the improvement of the assessment models' robustness, recognizing and managing risks (Nahiduzzaman et al., 2015) and opportunities, identifying causal relationships, developing models sensitive to subjective vulnerability, inclusion of participatory processes in which vulnerable sections are taken into account, as well as the incorporation of the complexity and multi-scale nature of vulnerability into the characterization methods (Adger, 2006). Along with capturing UVA's subjective side, which consists of a experiencing of stimuli due to subjective, non- material considerations, also grasping the dynamic character of vulnerability has been marked out as a challenge for vulnerability research (Adger, 2006). Table 2 summarizes the set of requirements of both USP and UVA lying the foundations of the analytical framework used to review the identified assessment methods (section 3.2), and makes explicit their interconnection as responses for the identified common challenges 


\section{Conceptual framework for UVA}

This section introduces the conceptual framework used to assess to what degree advances on the above research objectives have been made. This scheme focuses on four different aspects of the assessment methods, namely their approach, stimuli, development stage and addressed requirements of research directions. While the first three aspects relate to the generic attributes of evaluation methods allowing a qualitative analysis, the latter has to do with the quantitative aspect of the research effort made, and serves as the basis for the analytical framework whence the advancement made on the research required has been assessed.

\subsection{Generic attributes}

\subsubsection{Approach}

Upon the basis of the works carried out by Brooks (2003) and Füssel and Klein (2006), the UVA methods are classified according to the following typologies:

a) Biophysical approaches, in which the vulnerability concept arises from non-human factors.

b) Social approaches, relating to human behavior and societal characteristics.

c) Comprehensive approaches, in which both biophysical and social factors are taken into account for the vulnerability characterization.

\subsubsection{Stimuli}

Stimuli refer to the type of perturbation acting upon the entity. A wide range of stimuli can be considered (Wolf et al., 2013). Therefore, a brief review of the selected studies was carried out, resulting in the following groups of hazards: seismic, water flooding, generic natural, underground infrastructure operational failure, surface infrastructure operational failure, and social affairs. So far as these stimuli are susceptible of having been produced by others or not, these have in turn been respectively classified as 2 nd or 
1st Order stimuli.

\subsubsection{Developmental stage}

Developmental stage: The classification of developmental stages, including the impact, vulnerability, and adaptation assessment categories, was determined according to Füssel et al., (2006) (Table 2).

\subsection{Research attributes}

The final, core stage of the analysis looked at the research requirements addressed in the evaluated methods. The common requirements for both USP and UVA, which in Table 2 are related to the developmental stages, are:

3.2.1 To be robust, as a way to cope with uncertainty.

Robustness can be understood as the ability of a model to withstand variations in the inputs without experiencing significant changes in its output.

As an instance of robustness assessment, consider two possible indicator-based assessment models ranking a set of areas by their environmental vulnerability (Andres et al., 2017), in which the indicators are affected by uncertainty, represented as probability distributions. If we run each assessment model many times, as in a Monte Carlo simulation (Penades-Pla et al., 2016), changing each time the values of the indicators according to the given distributions, we obtain a new ranking each time we run the model. For each model thus evaluated, its robustness would be assessed as the inverse of the variance attached to the set of new rankings obtained, i.e., the more robust model will be that in which the rankings varied the least.

3.2.2 To have the ability to incorporate participatory processes and to take into account subjectivity

The engagement of stakeholders has become usual in USP. However, citizen involvement in the planning process is still a challenge for both USP and UVA; it can be handled by 
means of the implementation of participatory processes (McCormick, 2016) such as those already present in environmental assessment (O'Faircheallaigh, 2010). Public participation involves the transmission of information to decision makers by the public, and may help the smooth implementation of projects or programs. Moreover, through social learning, these participatory processes can provide the social point of view and the preferences needed for grasping the subjective character of vulnerability (Malekpour et al., 2015), as has been requested for UVA assessment methods. This subjective side refers to how people's experience of the same event differs (Adger, 2006) and it is, therefore, a relative, context-dependent concept (Cutter et al., 2003).

\subsubsection{To take into account complexity and the multiplicity of scales.}

Since vulnerability is context-dependent and of a complex nature (Adger, 2006), taking this into account requires dealing with complexity. Besides, the relations between any urban element and its context are, in the case of urban fabrics, somehow hierarchical, for example, neighbourhoods are contextualized by cities, which in turn are contextualized by provinces, and so on. This socio-political, multi-scale character of UVA is somewhat similar to the well-known layering of an environmental assessment (EA), represented as a linear cascade of rules and action which starts with an assessment at the policy level, descends to the levels of plans and programs, and ultimately ends with an EA at the project level (Slootweg \& Jones, 2011). Therefore, comprehensive approaches shall consider the relations of each element not only within its own scale, but crossing the multiple layers composing urban vulnerability. In a similar vein, the adoption of holistic approaches is recommended to perform accurate environmental assessments of complex systems, such as territories, providing an integrated assessment of entities in a territory from local to overall scales (Loiseau et al., 2012). Such approaches to dealing with complexity are already embodied in cascade-failure methods, tracing, for a system, the chain of events leading to the production of effects as a consequence of the partial or total 
failure of one or more of its sub-systems.

3.2.4 To have the capacity to capture the dynamic nature of urban vulnerability.

Since vulnerability is context-dependent, and this context changes, methods intended to take into account the dynamic nature of UV should consider it rather as an evolution than as a static state, unconnected with others, corresponding to a given situation. Therefore, those aspects in terms of which the context changes, such as time or politicaladministrative scale, are significant criteria in terms of which to define vulnerability, as well as to understand the underlying dynamics of any environmental system (Slootweg \& Jones 2011). For this reason, UVA assessments should provide not only the current vulnerability state, but also the risk of becoming more vulnerable over time (Adger, 2006; Birkmann et al., 2014). On the other hand, just as the characterization of EA dynamics demands taking into account the interactions between the scale being analyzed and those scales above and below it (Slootweg \& Jones, 2011), so UVA methods need to relate entities of one scale with the corresponding entities in the scales above and below.

\subsubsection{Manage multiple objectives}

Since stakeholder involvement in planning provides different interests to take into account, which can eventually be in dispute, methods allowing for simultaneously analysing the issue at stake from the perspectives of the multiple interests affected are demanded. This feature cannot but contribute to enhance the capacity of overcoming conflicts of interest that may arise during the planning process, allowing the adoption of strategies partly satisfying several, eventually conflicting requirements, instead of fully satisfying one given objective alone, as in the case of a mono-objective approach. Take, for example, the case where a town's inhabitants must determine the amount of allowable pollution that can be emitted by a factory into a nearby lake over a given planning horizon (Hadka et al., 2015). By means of a multi-objective approach, the inhabitants will be enabled to take their decision after having observed the problem from the points of view 
of minimizing phosphorus in the lake, maximizing economic benefit, maximizing inertia, and maximizing reliability. Besides, they will have a set of compromise solutions at their disposal from which to choose.

\subsubsection{To make use of cognitive approaches}

Some assessment techniques provide information concerning the trade-offs between the criteria framing the UV concept assessed, therefore enhancing the identification of causeeffect relations. This information may be transformed, by means of its analysis within the assessment method, into knowledge valuable for the process. In consequence, techniques such as multi-objective optimization, when implemented in methods such as discursive approaches, allow the exploitation of the information generated, affording knowledge which can be dynamically used to improve the model, or guide its development. Following the example of the point above, the multi-objective approach employed for the environmental assessment of the situation with the lake lets the inhabitants draw conclusions regarding the relations between the objectives, which enabled them to learn the dependencies between their decisions and the system's performance, and discover the cost-benefit compromises offered by various strategies.

\section{Methodology: selection of studies}

Once an analytical framework for the review of UVA methods was established, a literature review was carried out to elucidate the advancement of urban vulnerability models. A four-step process was used for this purpose. In the first step, a comprehensive search was conducted under the Title/Keyword/Abstract (T/K/A), data range and subject area fields of the search engines Scopus and Web of Science. Urban vulnerability was the term used in the T/K/A search field. Since our aiming was to find out the current trend on UVA research, we focused our revision in methods developed in the last years. The cutoff year of the search was determined upon the basis of the latest study found reviewing urban vulnerability research (Romero Lankao \& Qin, 2011). This latter, 
although focused on the conceptualization rather than on the assessment of UV, summarized previous research, and identified several research directions. In addition, being the aim of this work the role that urban vulnerability plays into strategic urban planning, only "social sciences" and "engineering" were selected as subject areas for the search. In the second step, a forward search carried out, by means of which more works developing new UVA methods were identified. $24.29 \%$ of the articles reviewed were unreferred in further works, while $49.22 \%$ and 26.49 were cited between 1 and 5 times, and six or more, respectively. Only $7 \%$ of all the UVAs analyzed were cited in new methods henceforward developed, which might be understood as a low performance as inspiration source. In the third step, a brief review of the resulting studies was performed, selecting those whose relationship with urban vulnerability was asserted through evaluating the title's meaning. Finally, as fourth step, a content analysis of the selected papers was followed to identify those studies including UVAs, resulting in 65

publications. An evaluation was then conducted to ascertain to what degree the advances had been achieved as far as the current urban vulnerability research objectives were concerned.

\section{Results, descriptive analysis of the research effort made}

This section examines the selected urban vulnerability assessment methods upon the basis of the above conceptual framework (section 3.2), highlighting the main findings regarding with the evolution of UVA methods. Therefore, results shaping and contextualizing the state of UVA were presented, and a discussion tackling the research effort made for the UVA methods in general was ensued. For the analysis of the resulting data, the statistical software Minitab 17 was employed.

\subsection{Contextualization of UVA}

Table 3 shows that biophysical, comprehensive and social approaches had nearly the same proportion. A current trend was inferred for the biophysical and comprehensive 
schools of thought, whose higher means depicted their increasing growth.

Taking account of their means and standard deviations (SDs), Table 3 reveals an increasing relevance (higher mean), for the latter years, of assessments dealing with the infrastructure-related stimuli, which are water flooding, storms, surface infrastructure failures and underground infrastructure failures, the latter being prone to social approaches. Table 3 also displays the affinity of the "seismic" and "surface infrastructure failures" stimuli for the biophysical methods (lower approach mean).

Having resulting a p-value of 0,093 in the Welch's test, one way anova (90\% CI) between approach and developmental stage revealed a significant influence of the former on the latter, in such a way that the comprehensive approaches directly promote an increase in developmental stage towards the adaptation stage (Figure 1), while the biophysical approach underpins that of the impact stage.

Table 3 shows that the development course is stalled within the vulnerability assessment stage, in which social approaches play the most important role. However, a slight, yet non-significant increasing trend of the relative importance of the adaptation and, to a lesser extent, impact stages, can be perceived from 2014 onwards (Figure 2). This may be explained by the previously stated relations between, on the one hand, infrastructurebased stimuli with the biophysical and comprehensive approaches, and on the other hand, biophysical and comprehensive approaches with the impact and adaptation stages, respectively.

\subsection{Research effort made}

In this section, effort made in the research of UVA methods is evaluated by means of a descriptive analysis, firstly, of the number of requirements tacked by the papers reviewed, and secondly, of the overall attributes mentioned in section 3.1.

\subsubsection{Number of requirements}

The ratio of undertaken requirements was 0.54 per assessment method reviewed, as 
shown Table 4. It can also be observed that most of urban vulnerability assessments were related to robustness and the cognitive-cause effect, while the presence of the other requirements is far lower. Table 4 "Relative (2)" column makes explicit this heterogeneity, encouraging further analysis of its inner structure. For the purpose, a clustering approach upon the basis of the number of observations, whose results are shown in Figure 3, was carried out. Three clusters, referring on the one hand to the attention paid to each research line, and on the other hand to the similarities in their behavior, were identified.

Nearly half of the reviewed publications do not aim at the attainment of any of the identified research requirements (Table 5). Furthermore, they present a very low performance when it comes to incorporating various requirements at once, with a maximum of three. This states a low level in methods seriously attempting to embrace many of the previously highlighted aspects, and thus a poor performance when it comes to taking advantage of the foreseeable profits that are to be expected from an integrated effort (Romero Lankao \& Qin, 2011). Given their means and standard deviations, Table 3 reveals that assessments bearing no research requirement are confined within the vulnerability assessment stage (mean below 2 and lowest SD), while those embodying two or more tended to adaptation (higher means and SD).

\subsubsection{Generic attributes}

Bearing in mind both the time trends as the activity displayed in relation to the requirements achievement, four groups can be inferred from Table 6, i.e. continuously active, discontinuously active, continuously passive and discontinuous passive, trends. The first is characterized by an important growth from 2012 to 2014, sustained thereafter, encompassing the robustness and cognitive requirements. The second, which refers to the participatory, experiences a sudden and pronounced increase from 2013 to 2014, 
disappears in 2015 only to rise again in 2016. The third group is composed of the requirement urban dynamics, and its lines show an almost constant behavior, as well as a low activity. Finally, the fourth group, which represents the multi scale-complexity and multi-objective requirements, is almost unnoticed until 2013, with an unexpected and weak appearances in 2014, and two and one more observations respectively in 2016. Despite the low amount in the number of studies, an increase in the presence of research requirements was detected for the later years.

Table 6 portrays the relationships between the aspects 'research requirements' and 'approach', stating that it is the biophysical and comprehensive approaches whence the greater research effort comes, especially for the robustness-uncertainty, and cause-effect research lines respectively.

Table 6 gathers the number of research requirements in terms of stimuli, so that two groups were identified: the first composed of those stimuli in which the sum of all pursued requirements is between 2-3 observations, and a second in which the sum ranges between 12-14-17 (natural generic, seismic and flooding respectively). Otherwise, water flooding was the only hazard whose dealing had promoted all research requirements, closely followed by the seismic and natural generic stimuli, these latter being present in four of the five research directions. This, together with the fact that they had more observations in terms of research requirements, evidences that natural generic, seismic and water flooding-storm were, for the short term, the type of stimuli where most progress, in terms of research intensity and diversity, was to be expected. As far as the future is concerned, however, the so-called infrastructure-related stimuli yielded better prospects, due to their increasing ascendancy.

\section{Analytical framework and discussion on the advancement made}

In this section we assess to which extent, the requirements arisen for UVA in the light of the advancement made on USP, have been operationalized on the former. For the purpose, 
firstly an analysis and consequent discussion of advancement made for each of the research lines (3.2) was conducted, and secondly a description of the relationships linking the research with the generic attributes (3.1) was provided.

\subsection{Analysis of each research attribute}

\subsubsection{Robustness}

Robustness is the most frequent requirement (Table 6) across all developmental stages, and also in the two main approaches. Additionally, from 2010 to present, except in 2014 and 216, robustness was observed the most, exhibiting an active and continuous behavior (Section 5.2). Therefore robustness is currently the main research line in the field of UVAs.

Table 7 provides insights for qualitative analysis of the state of robustness. Robustnessrelated studies were grouped according to the technique used to model uncertainty, and classified into the following categories: incremental, modeling-managerial or discursive approaches (Dominguez et al., 2011). Most of the studies addressing uncertainty were simulation-based, i.e. they attempt to reproduce the real world. Of these, $12 \%$ were based on complex network models such as cascade-failure methods (Sun et al., 2015), focusing on the relations between discrete objects within a network, while $6 \%$ employed fuzzy set theory to build a probabilistic model based on the load and resistance principle from reliability engineering. $24 \%$ used other types of models, such as a combination of the probabilistic method and statistical models, or the project pursuit approach.

Scenario planning, which is considered to be adequate for handling future uncertainties (Dominguez et al., 2013) and falls within the integrated strategic planning context (Malekpour et al., 2015; Dorning et al., 2015), was commonly used, accounting for 25\% of the studies fostering uncertainty. The former technique, when combined with cognitive approaches, relates to the discursive stage (Bristow \& Brumbelow, 2013; 
Giardina et al., 2015; Lemonsu et al., 2015). Complex network models, which is akin to an uncertainty managerial approach, allow nodes to be assigned with certain degrees of freedom, were also commonly found. The use of simulation-based models was found to be most extensive in studies from 2012 onwards. Modeling uses fuzzy set theory to perform probabilistic-based models. Sensivity analysis had also been used for robustness assessment (Marull et al, 2007).

\subsubsection{Participatory}

Despite the important interest that arose from this requirement (22\% of Table 6 total share), from a qualitative point of view, the employment of the participatory process for grasping subjectivity is shown to be rather immature and lacking in steadiness. However, due to its strong involvement in assessment methods disclosed in 2016 bearing multiple requirements, its performance was good when it came to integrating this requirement with others.

From the stimuli point of view, this requirement is untold among UVAs dealing infrastructure-related stimuli. Alguacil Gómez et al. (2014) and Lee et al. (2009) proposed methods aiming to grasp the subjective side of urban vulnerability, i.e., how people experience change (Adger, 2006), by considering the assessment of indices intended to quantify that subjectivity. However, in this study, the assessment is obtained exclusively from the opinion of the head of the area of urban planning in each of the municipalities analyzed, rather than from people who came from vulnerable sections themselves (Adger, 2006). Kimani-Murage et al. (2014) went a step further by putting forth a more extensive survey in order to assess how the affected inhabitants defined, perceived and experienced crisis. Another qualitative step forward was taken by Moradi et al. (2014) when assessing the degree of subjectivity in expert judgement, and its possible influence on the decision-making process. The latter is an important issue due to the fact that taking into account the participatory process is a necessary, but not 
a sufficient condition (Munda, 2004), and thus some kind of weighting should be provided to allow for aggregation of the results provided by participatory processes. The majority of the other studies assessed make a basic use of participatory processes, incorporating experts to the evaluation process when using a qualitative approach, or have to weight variables.

These advances, however, fail to bridge gaps like a lack of processes for identifying all critical stakeholders rather than only those of the vulnerable sections (de Graaf \& Dewulf, 2010), and the pending development of tools for channeling public participation into assessment processes (Shiehbeiki et al., 2014). This leads to the assertion that the participatory-subjectivity requirement, despite having theoretical foundations for its proper development, is disconnected from the trend at the forefront of urban vulnerability research. The implementation in UVA methods of participatory processes entailing high stakeholders and citizen involvement would help reverting this situation first by incorporating the social point of view, second by providing the required consensus on the weighting scores needed to start-up the vulnerability assessment process, and last by furnishing the evaluation process with the required feed-back. This way, representation and legitimacy will be guaranteed on the process, which becomes truly bottom-up. To this, the development of other research lines can also contribute by providing the stakeholders with an enriched knowledge though the employment of multiobjective as a cognitive approach,

\subsubsection{Complexity-multiscale}

With only a $6 \%$ total share, from a quantitative point of view, the "complexitymultiscale" research line, together with that of multi-objective, received the least research interest. Having appeared just three times (Koks et al., 2015; Rosenzweig et al., 2011; Shuang et al., 2014), neither a yearly, nor other trends can be clearly inferred, as shown in Table 6. It is surprising that, although existing references point out its importance for both UVA (Adger, 2006; Romero-Lankao et al., 2014) and USP (Giezen et al., 2015; 
Pemberton \& Searle, 2016; Lundqvist, 2016; Carmo, 2013; Toubin et al., 2015), so little attention has been paid to multi- scale. Furthermore, as trans-disciplinary approaches are proper for tackling complexity (Smith \& Jenkins, 2015), this lack of integration suggests that its research strategy is misled. Several techniques for dealing with complexity and multi-scale, such as Monte- Carlo simulation, spatial auto-correlation (F. Dormann C. et al., 2007; Uejio et al., 2011), some simulation-based techniques such as survival analysis combined with cellular automatas (Chen et al. 2016), the syndrome approach (Romero Lankao \& Qin, 2011) or cascade-failure methods (Sun et al., 2015), which have already been used in field of USP, can help remedy this undesirable situation.

\subsubsection{Urban dynamics}

The cluster analysis displayed in Figure 3 reveals that this requirement, stands alone forming the under-researched group. Besides, it shapes the continuously passive behavior group identified previously. Table 6 shows that water flooding-storm stimuli are those most akin to dynamic nature research, and points out similarities between dynamic and multi-objective both in the number of observations and in integration. It is present both for every approach, and, as multi-objective, mainly in the vulnerability assessment, but in the adaptive assessment developmental stages. Dynamic programming, fuzzy logic and simulation-based optimization models have been used by some of the methods reviewed to deal with the dynamic nature of some environments (Juan et al., 2015), as well as combining linear programming with genetic algorithms (Long \& Li, 2014). Multiobjective optimization techniques, such as genetic algorithms, have been used in urban vulnerability research to deal with uncertainty (Bristow \& Brumbelow, 2013), an advance to which the 'dynamic nature' research line has not yet joined. Ahmad et al. (2013) made an attempt to grasp the dynamic nature of urban systems by focusing on the dynamic state of a system, i.e. on the balance relation between the so-called theory of load and resistance forces, which can ease or oppose to changes to be accepted in a system, respectively. In any case, due both to the importance attributed to dynamic nature and to 
its low-to- medium quantitative profile, our assessment considers the progression made to be insufficient. This is a somewhat limited advance from the situation depicted by Pamungkas (2013), when this worker stated that there had been no progress in this research line at all.

\subsubsection{Multi-objective}

The multi-objective research line showed several similarities with robustness. As can be observed in Table 6, the sorting of approaches, from major to minor, by number of cases (biophysical-comprehensive-social), turned out to be the same for both. For both of them, as well, the seismic and water-flooding stimuli were the main ones. On the other hand, robustness and multi-objective differ significantly in one aspect, namely the proportion of effort bestowed to them (Table 6). Notwithstanding this difference, similarities prevail sufficiently as to form a cluster, composed of multiobjective, robustness and cognitive requirements, referred to above as the highly researched cluster (Figure 3).

In two of the three studies where the presence of multi-objective research lines was detected, MOO algorithms were incorporated into approximate solutions: In Esmaeili (2014) and Bristow \& Brumbelow (2013) respectively, MOO-genetic algorithms and simulation techniques were combined to also deal with uncertainty, thus belonging to the so-called sim-heuristics techniques. The latter embody both simulation and heuristic optimization, whose capacity for dealing with real-life uncertainty is regarded as proven (Juan et al., 2015). The evaluation method proposed by Bristow \& Brumbelow (2013) confirmed this synergy between heuristics and simulation, and presented advances in the 'robustness-uncertainty' related research line. Therefore, it can be concluded that the 'multi-objective-strategic capacity' research requirement presents medium-low and medium-good performances from quantitative and qualitative perspectives, respectively.

\subsubsection{Cognitive}


In Table 6, the cognitive requirement is ranked second in terms of qualitatively leading the research lines across all developmental stages, as in most approaches. The yearly distribution showed an important increase in 2013, which had been sustained through 2014, 2015 and 2106, following almost the same trend as robustness. It has been mainly applied to deal with the seismic and natural general stimuli, appearing integrated in a third of its observations; consequently, this requirement ranked second in terms of integration capacity. Furthermore, its combination with other research lines led to a qualitative increase in the latter, as in the case of discursive approaches for dealing with uncertainty (Dominguez et al., 2011). Examples of this were found among the studies reviewed. Giardina et al. (2015) embodied both cognitive and robustness requirements, while Bristow \& Brumbelow, (2013) embraced the requirements of robustness, multiobjective and cognitive, to perform the most integrative method. Also noteworthy is that cognitive, along with the robustness requirement formed the so-called continuously active (section 5.2), and is also related with the also highly researched participatory requirement (Fig 3, dot and Dash line). This provides evidence not only of the significant attention paid to this requirement, but also of the synergistic relation between "robustness" and "cognitive", easing discursive approaches to which multi-objective can also contribute (Yepes et al., 2015).

\subsection{Relationships between research and generic attributes}

As to the relationship between research requirements and the generic characteristics defined in section 3, Table 6 also depicts the attention paid to each requirement by the developmental stages, highlighting robustness, participatory and cognitive as the most attractive for researchers of whatever developmental stage, especially for those of vulnerability assessment. From this table we can infer, besides, that those two requirements are also highly correlated with the group of those stimuli amounting the greater number of observations, composed by the stimuli natural generic, flooding and 
seismic.

Regarding the relation of requirements with the type of approach, most of them were equally spread among all approaches. On the contrary, research on robustness, and to a lesser extent on multi-objective, were distinctly showing their reliance on the biophysical approach for the developed by now attained. Therefore, considering on the one hand that biophysical approaches underpinning robustness are showing an increasing trend, and on the other hand that the robustness requirement is among the requirements identified in the research effort section as exhibiting an active behavior (section 5.1), the better prospects can be expected for the development of more research on this issue. It is pending, yet, furthering in its implementation into UVAs arisen from socio-economic or comprehensive approaches.

\subsection{Policy implications}

Given the leading role of infrastructure-related UVAs, we suggest policy-makers to boost this trend by promoting the incorporation of UVA methods within the infrastructure planning process. Given the close connection between UVA and USP evolutions, that incorporation would be a natural way of contributing the advancement of UVA research.

On the other hand, by following our suggestions UVA methods will be ensued that affords policy-makers with comprehensive assessments in which the different socio-political scales conforming a territory are linked. This, on the one hand, will enable policy-makers to rise plans, coordinated throughout scales, in which entities ranging from national to municipal scales are evaluated under a same model.

Finally, to convey those plans across institutional scales, however, may require the adoption of new policy measures. This task may be facilitated by the adoption, in the development of the assessment model, of bottom-up strategies, which the current UVA 
trend advocates since it promotes:

- Citizen and stakeholder involvement by which to ensure representation and legitimacy, and soften the implementation of plans.

- The incorporation of methods fostering robustness, as a way for dealing uncertainty, in which stakeholders are taken into account at the beginning of the process.

- Multi-Objective modelling accounting for stakeholders' interests, to embody the Cognitive approach providing stakeholders with a better understanding of the model.

- The consideration of the multiple socio-political scales embodied in a territory and their linkages, thus providing a transmission chain along institutional scales from bottom to top.

\section{Conclusions}

First, this paper traced a common evolutive path for both urban strategic planning and urban vulnerability assessment, with the former paving the way. This path runs through a series of waypoints, in the form of research requirements that are shared by both strategic planning and vulnerability assessment. Six common research objectives (viz. increase of robustness, for dealing with uncertainty, embodiment of participatory processes to grasp subjectivity, consideration of the multiscale and complex nature of the subject as well as its dynamic character, account for multiple objectives to gain strategic capacity and to implement cognitive outlooks that can provide insights of causeeffect relations) are generalized from this track.

Secondly, upon the basis of the above, an analytical framework considering other relevant 
aspects, such as the types of stimuli that occur, approaches that deal with them, and the developmental stage, is formed to evaluate the current state of the advances made in the assessment of urban vulnerability. Thirdly, for the purpose of grasping current trends in research, a review of the studies related to urban vulnerability from 2010 onwards was conducted, upon which an evaluation grounded in the aforementioned analytical framework was developed. Its main findings, attempting to evaluate current advances, are the following:

- With almost half of the analyzed studies undertaking any research requirements, and a significant decrease in its number, the UVA methods' quantitative prospects do not promise an increase in interest in the subject, nor advances in its developmental stage, but rather a stagnation. This means a setback with respect to trends identified in 2011, when growing interest was foreseen (Romero Lankao \& Qin, 2011; Tonmoy et al., 2014); This, in fact, was sustained until 2014, but is absent today. However, the number of studies regarding the so-called infrastructure-related stimuli, arising mainly from the biophysical domain, prevail, and are consequently gaining ground within the UVA field (Section 5.1), thus increasing the overall research performance (Section 5.2).

- Due both to the heterogeneity in the attention paid to them and to similar behaviors, the identified research lines can be grouped into a first, second and third cluster, recording significant, limited and almost null advances respectively (Table 8). The first embraces those requirements arousing the most interest (Table 6), relating mainly to methods simultaneously embodying multiple research lines and, in the case of robustness and cognitive, whose qualitative development is not far from that of strategic planning. The second performs low-to-medium/good in a quantitative and a qualitative sense respectively, and is composed of the multi-objective alone. Finally the third, involving the urban dynamics and complexity-multiscale requirements, to which less 
attention was bestowed, yields a medium-to-low performance in proximity to the strategic planning advances.

- The 'approach/school of thought' aspect, whose biophysical and comprehensive levels promote the impact and adaptation stages of UVA's evolution respectively, significantly influences the latter.

Thirdly, the relations identified allow us to envisage a desirable future taking the UVA out from its current evolutionary stagnation, promoting more integrative methods and embodying those requirements more akin to comprehensive approaches. In order to reach it, assessment methods not limited to but especially fostering research on cognitive, multi-objective and under-researched requirements should be encouraged. As well, the promotion of methods incorporating uncertainty into social and comprehensive approaches is still pending, and therefore deserves more research effort. Since USP largely provides the required tools and can develop new ones, and that the proposed scenario implies a qualitative swap rather than a quantitative increase, this can and should be attained. Therefore, a shift in the research focus, bridging the detected qualitative gaps and driving progress in the evolutionary scale, should be set up. Due to their good performance in their capacity for bearing simultaneously multiple research lines, and to their growing importance for the research community, the assessment methods related to "water logging and storm", "underground infrastructure failure" and, to a lesser extent, "surface infrastructure failure" are called upon to lead the future advances.

Thus, for the purpose of and with the aim of taking advantage of their growing ascendancy, this paper encourages all workers in this field, but especially those developing urban vulnerability assessments on infrastructure-related stimuli, to enhance their methods through a shift in their focus towards the integration of specially the cognitive, multi-objective, complexity-multiscale and dynamic research requirements described in this work., and by the adoption of advanced methods dealing with 
uncertainty. This way, they may capitalize our findings by achieving more advanced UVA methods which, on the other hand, would also profit policy makers and planners due to the improvement of knowledge entailed by the cognitive approach promoted in our work.

Notwithstanding the amount of papers analyzed, the scope of this research, focused on works carried out from 2011 onwards and hence representing a tip of the iceberg on this topic, impose limitations on the concretion level of the possible conclusions. Therefore, the assertions made should be understood rather as guidelines based on the identified current trends, than as concrete measures.

Besides, the qualitative part of the analysis mainly relies in an overall, instead of case-bycase, assessment of each research line. In consequence, the promotion of complementary works taking a deeper look on each research line, by means of a deeper analysis of their qualitative development within a narrower span of time, appears as of necessity for the proper implementation of such requirements on UVA methods.

\section{References}

Adger, W. N. (2006). Vulnerability. Resilience, Vulnerability, and Adaptation: A CrossCutting Theme of the International Human Dimensions Programme on Global Environmental Change Resilience, Vulnerability, and Adaptation: A Cross-Cutting Theme of the International Human Dimensions Programme, 16(3), 268-281. http://doi.org/http://dx.doi.org/10.1016/j.gloenvcha.2006.02.006

Ahmad, S. S., \& Simonovic, S. P. (2013). Spatial and temporal analysis of urban flood risk assessment. Urban Water Journal, 10(1),-49.

http://doi.org/10.1080/1573062X.2012.690437

Aina, Y. A., \& Aleem, K. F. (2014). Assessing the vulnerability of an industrial city to predicted sea level rise using SRTM and GPS observations: The case of Yanbu, Saudi Arabia. International Journal of Geoinformatics, 10(3), 73-81.

Albuquerque, M. T. D., Sanz, G., Oliveira, S. F., Martínez-Alegría, R., \& Antunes, I.

Alguacil Gómez, J., Camacho Gutiérrez, J., \& Hernández Aja, A. (2014). La vulnerabilidad urbana en España. Identificatión y evolutión de los barrios vulnerables. Empiria, (27), 73-94. 
An, S., Cui, N., Wang, J., \& Yu, H. (2011). Simulation and Analysis of Emergency Routing Planning Based on Vulnerability Identification of Urban Transportation Network. In Transportation and Development Institute Congress 2011 (pp. 11881205). Reston, VA: American Society of Civil Engineers. http://doi.org/10.1061/41167(398)114

Andres Fernandez, M., Bucaram, S., \& Renteria, W. (2017). (Non-) robustness of vulnerability assessments to climate change: An application to New Zealand. JOURNAL OF ENVIRONMENTAL MANAGEMENT, 203(1), 400-412. http://doi.org/10.1016/j.jenvman.2017.07.054

Armaş, I., Ionescu, R., Gavriş, A., \& Toma-Danila, D. (2016). Identifying seismic vulnerability hotspots in Bucharest. Applied Geography, 77, 49-63. JOUR. http://doi.org/10.1016/j.apgeog.2016.10.001

Birkmann, J., Garschagen, M., \& Setiadi, N. (2014). New challenges for adaptive urban governance in highly dynamic environments: Revisiting planning systems and tools for adaptive and strategic planning. Urban Climate, 7, 115-133.

Bosiljkov, V., D'Ayala, D., \& Novelli, V. (2014). Evaluation of uncertainties in determining the seismic vulnerability of historic masonry buildings in Slovenia: use of macro-element and structural element modelling. Bulletin of Earthquake Engineering, 13(1), 311-329. http://doi.org/10.1007/s10518-014-9652-7

Bradford, K., Abrahams, L., Hegglin, M., \& Klima, K. (2015). A Heat Vulnerability Index and Adaptation Solutions for Pittsburgh, Pennsylvania. Environmental Science \& Technology, 49(19), 11303-11311. article. http://doi.org/10.1021/acs.est.5b03127

Bristow, E. C., \& Brumbelow, K. (2013). Simulation to Aid Disaster Planning and Mitigation: Tools and Techniques for Water Distribution Managers and Emergency Planners. Journal of Water Resources Planning and Management, 139(4), 376-386. http://doi.org/10.1061/(ASCE)WR.1943-5452.0000283

Brooks, N. (2003). Vulnerability, Risk and Adaptation: A Conceptual Framework. Tyndall Centre for Climate Change Research, University of East Anglia, Norwich, UK.

Cagno, E., De Ambroggi, M., Grande, O., \& Trucco, P. (2011). Risk analysis of underground infrastructures in urban areas. Reliability Engineering \& System Safety, 96(1), 139-148. http://doi.org/10.1016/j.ress.2010.07.011

Cai, Y., Cao, Y., Li, Y., Huang, X., \& Tan, Y. (2014). Identification of vulnerable lines in urban power grid based on voltage grade and running state. Zhongguo Dianji Gongcheng Xuebao/Proceedings of the Chinese Society of Electrical Engineering, 34(13), 2124-2131. http://doi.org/10.13334/j.0258-8013.pcsee.2014.13.014 
Carmo, R. M. (2013). Polycentrism as a Multi-Scalar Relationship Between Urban and Rural Areas: The Case of Portugal. EUROPEAN PLANNING STUDIES, 21(2), 149-166. http://doi.org/10.1080/09654313.2012.722912

Carreño, M. L., Cardona, O. D., \& Barbat, A. H. (2011). New methodology for urban seismic risk assessment from a holistic perspective. Bulletin of Earthquake Engineering, 10(2), 547-565. http://doi.org/10.1007/s10518-011-9302-2

Chang, L.-F., \& Huang, S.-L. (2015). Assessing urban flooding vulnerability with an energy approach. Landscape and Urban Planning, 143, 11-24. http://doi.org/http://dx.doi.org/10.1016/j.landurbplan.2015.06.004

Chen, Y., Li, X., Liu, X., Ai, B., \& Li, S. (2016). Capturing the varying effects of driving forces over time for the simulation of urban growth by using survival analysis and cellular automata. Landscape and Urban Planning, 152, 59-71. http://doi.org/10.1016/j.landurbplan.2016.03.011

Chen, S., Xue, Z., Li, M., \& Zhu, X. (2013). Variable sets method for urban flood vulnerability assessment. Science China Technological Sciences, 56(12), 31293136. http://doi.org/10.1007/s11431-013-5393-0

Chiauzzi, L., Masi, A., Mucciarelli, M., Vona, M., Pacor, F., Cultrera, G., et al. (2011). Building damage scenarios based on exploitation of Housner intensity derived from finite faults ground motion simulations. Bulletin of Earthquake Engineering, 10(2), 517-545. http://doi.org/10.1007/s10518-011-9309-8

Christodoulou, S. E., \& Fragiadakis, M. (2015). Vulnerability Assessment of Water Distribution Networks Considering Performance Data. Journal of Infrastructure Systems, 21(2), 04014040. http://doi.org/10.1061/(ASCE)IS.1943-555X.0000224

Codjoe, S. N. A., \& Afuduo, S. (2015). Geophysical, socio-demographic characteristics and perception of flood vulnerability in Accra, Ghana. Natural Hazards, 77(2), 787-804. article. http://doi.org/10.1007/s11069-015-1624-y

Conway, D., Li, C. Q., Wolch, J., Kahle, C., \& Jerrett, M. (2008). A Spatial Autocorrelation Approach for Examining the Effects of Urban Greenspace on Residential Property Values. The Journal of Real Estate Finance and Economics, 41(2), 150-169. http://doi.org/10.1007/s11146-008-9159-6

Cutter, S. L., Boruff, B. J., \& Shirley, W. L. (2003). Social vulnerability to environmental hazards. SOCIAL SCIENCE QUARTERLY, 84(2), 242-261. http://doi.org/10.1111/1540-6237.8402002

de Graaf, R. S., \& Dewulf, G. P. M. R. (2010). Applying the lessons of strategic urban planning learned in the developing world to the Netherlands: A case study of three industrial area development projects. Habitat International, 34(4), 471-477. 
Deng, Y., Li, Q., \& Lu, Y. (2015). A research on subway physical vulnerability based on network theory and FMECA. Safety Science, 80, 127-134. http://doi.org/10.1016/j.ssci.2015.07.019

Ding, M., Heiser, M., Huebl, J., \& Fuchs, S. (2016). Regional vulnerability assessment for debris flows in China-a CWS approach. Landslides, 13(3), 537-550. article. http://doi.org/10.1007/s10346-015-0578-1

Dominguez, D., Truffer, B., \& Gujer, W. (2011). Tackling uncertainties in infrastructure sectors through strategic planning: the contribution of discursive approaches in the urban water sector. Water Policy, 13(3), 299-316.

Dormann, C., M. McPherson, J., B. Araújo, M., Bivand, R., Bolliger, J., Carl, G., et al. (2007). Methods to account for spatial autocorrelation in the analysis of species distributional data: A review. Ecography, 30(5), 609-628. http://doi.org/10.1111/j.2007.0906-7590.05171.x

Dorning, M. A., Koch, J., Shoemaker, D. A., \& Meentemeyer, R. K. (2015). Simulating urbanization scenarios reveals tradeoffs between conservation planning strategies. Landscape and Urban Planning, 136, 28-39. http://doi.org/10.1016/j.landurbplan.2014.11.011

Duggal, B. (2014). Ranking on vulnerability index: An assessment of urban squatter settlements. Man in India, 94(1-2), 155-172.

Esmaeili, V. (2014). Integrated decision making model for urban disaster management: A multi-objective genetic algorithm approach. International Journal of Industrial Engineering Computations, 5(1), 55-70. http://doi.org/10.5267/j.ijiec.2013.08.004

Fang, C., \& Wang, Y. (2015). A comprehensive assessment of urban vulnerability and its spatial differentiation in China. Acta Geographica Sinica, 70(2), 234-247. http://doi.org/10.11821/dlxb201502005

Fernandez, P., Mourato, S., Moreira, M., \& Pereira, L. (2016). A new approach for computing a flood vulnerability index using cluster analysis. Physics and Chemistry of the Earth, 94, 47-55. article. http://doi.org/10.1016/j.pce.2016.04.003

Ferreira, T. M., Vicente, R., Mendes da Silva, J. A. R., Varum, H., \& Costa, A. (2013). Seismic vulnerability assessment of historical urban centres: case study of the old city centre in Seixal, Portugal. Bulletin of Earthquake Engineering, 11(5), 17531773. http://doi.org/10.1007/s10518-013-9447-2

Fekete, A. (2009). Validation of a social vulnerability index in context to river-floods in Germany. Natural Hazards and Earth System Sciences, 9(2), 393-403.

Fischer, K., Haering, I., Riedel, W., Vogelbacher, G., \& Hiermaier, S. (2016).

Susceptibility, vulnerability, and averaged risk analysis for resilience enhancement 
of urban areas. International Journal of Protective Structures, 7(1), 45-76. article. http://doi.org/10.1177/2041419615622727

Füssel, H.-M. (2007). Vulnerability: A generally applicable conceptual framework for climate change research. Global Environmental Change, 17(2), 155-167. http://doi.org/10.1016/j.gloenvcha.2006.05.002

Füssel, H.-M., \& Klein, R. J. T. (2006). Climate Change Vulnerability Assessments: An Evolution of Conceptual Thinking. Climatic Change, 75(3), 301-329. http://doi.org/10.1007/s10584-006-0329-3

Giardina, G., Hendriks, M. A. N., \& Rots, J. G. (2015). Damage Functions for the Vulnerability Assessment of Masonry Buildings Subjected to Tunneling. Journal of Structural Engineering, 141(9), 04014212. http://doi.org/10.1061/(ASCE)ST.1943-541X.0001162

Giezen, M., Salet, W., \& Bertolini, L. (2015). Adding value to the decision-making process of mega projects: Fostering strategic ambiguity, redundancy, and resilience. Transport Policy, 44, 169-178.

Guardiola-Víllora, A., \& Basset-Salom, L. (2015). Escenarios de riesgo sísmico del distrito del Eixample de la ciudad de Valencia. Revista Internacional de Métodos Numéricos Para Cálculo Y Diseño En Ingeniería, 31(2), 81-90. http://doi.org/10.1016/j.rimni.2014.01.002

Hadka, D., Herman, J., Reed, P., \& Keller, K. (2015). An open source framework for many-objective robust decision making. Environmental Modelling \& Software, 74(Supplement C), 114-129. http://doi.org/https://doi.org/10.1016/j.envsoft.2015.07.014

Harrison, P. A., Holman, I. P., \& Berry, P. M. (2015). Assessing cross-sectoral climate change impacts, vulnerability and adaptation: an introduction to the CLIMSAVE project. Climatic Change, 128(3-4), 153-167.

Juan, A. A., Faulin, J., Grasman, S. E., Rabe, M., \& Figueira, G. (2015). A review of simheuristics: Extending metaheuristics to deal with stochastic combinatorial optimization problems. Operations Research Perspectives, 2, 62-72. http://doi.org/http://dx.doi.org/10.1016/j.orp.2015.03.001

Kaji, H., Murao, O., Fujioka, M., Kanegae, H., Yamazaki, F., Estrada, M., \& Bisbal, A. (2014). A Simulation Model for Forecasting Urban Vulnerability to Earthquake Disasters in Lima, Peru: "LIMA-UVEQ." Journal of Disaster Research, 9(6), 1069-1077.

Karagiorgos, K., Thaler, T., Heiser, M., Hübl, J., \& Fuchs, S. (2016). Integrated flash flood vulnerability assessment: Insights from East Attica, Greece. Journal of Hydrology. article. http://doi.org/10.1016/j.jhydrol.2016.02.052 
Kaźmierczak, A., \& Cavan, G. (2011). Surface water flooding risk to urban communities: Analysis of vulnerability, hazard and exposure. Landscape and Urban Planning, 103(2), 185-197. http://doi.org/http://dx.doi.org/10.1016/j.landurbplan.2011.07.008

\section{Kelly, P. M., \& Adger, W. N. (2000). Theory and practice in assessing vulnerability to climate change and facilitating adaptation. Climatic Change, 47(4), 325- 352. http://doi.org/10.1023/A:1005627828199}

Kimani-Murage, E. W., Schofield, L., Wekesah, F., Mohamed, S., Mberu, B., Ettarh, R., et al. (2014). Vulnerability to food insecurity in urban slums: experiences from Nairobi, Kenya. Journal of Urban Health: Bulletin of the New York Academy of Medicine, 91(6), 1098-113. http://doi.org/10.1007/s11524-014-9894-3 King, R. A. R., \& Blackmore, K. L. (2013). Physical and political boundaries as barriers to the continuity of social vulnerability. Applied Geography, 44, 79-87. http://doi.org/http://dx.doi.org/10.1016/j.apgeog.2013.07.011

King, R. A. R., \& Blackmore, K. L. (2013). Physical and political boundaries as barriers to the continuity of social vulnerability. Applied Geography, 44, 79-87. http://doi.org/http://dx.doi.org/10.1016/j.apgeog.2013.07.011

Kirshen, P., Caputo, L., Vogel, R. M., Mathisen, P., Rosner, A., \& Renaud, T. (2015). Adapting Urban Infrastructure to Climate Change: A Drainage Case Study. Journal of Water Resources Planning and Management, 141(4), 04014064. http://doi.org/10.1061/(ASCE)WR.1943-5452.0000443

Koks, E. E., Jongman, B., Husby, T. G., \& Botzen, W. J. W. (2015). Combining hazard, exposure and social vulnerability to provide lessons for flood risk management. Environmental Science and Policy, 47, 42-52. JOUR. http://doi.org/10.1016/j.envsci.2014.10.013

Kotzee, I., \& Reyers, B. (2016). Piloting a social-ecological index for measuring flood resilience: A composite index approach. Ecological Indicators, 60, 45-53. http://doi.org/http://dx.doi.org/10.1016/j.ecolind.2015.06.018

Kriščiukaitiene, I., Baležentis, T., Galnaityte, A., \& Namiotko, V. (2015). A methodology for flood risk appraisal in Lithuania. Journal of Water and Land Development, 25(1), 13-22. article. http://doi.org/10.1515/jwld-2015-0008

Kumar, P., Geneletti, D., \& Nagendra, H. (2016). Spatial assessment of climate change vulnerability at city scale: A study in Bangalore, India. Land Use Policy, 58, 514532. JOUR. http://doi.org/10.1016/j.landusepol.2016.08.018 
Lee, B. J., Jang, T. Y., Wang, W., \& Namgung, M. (2009). Design Criteria for an Urban Sidewalk Landscape Considering Emotional Perception. JOURNAL OF URBAN PLANNING AND DEVELOPMENT-ASCE, 135(4), 133-140. http://doi.org/10.1061/(ASCE)UP.1943-5444.0000013

Lemonsu, A., Viguié, V., Daniel, M., \& Masson, V. (2015). Vulnerability to heat waves: Impact of urban expansion scenarios on urban heat island and heat stress in Paris (France). Urban Climate, 14, 586-605. http://doi.org/10.1016/j.uclim.2015.10.007

Liu, Y., Chen, J., He, W., Tong, Q., \& Li, W. (2010). Application of an Uncertainty Analysis Approach to Strategic Environmental Assessment for Urban Planning. Environmental Science \& Technology, 44(8), 3136-3141.

Long, H., \& Li, C. (2014). Vulnerability assessment of urban storm sewer systems. Shenzhen Daxue Xuebao (Ligong Ban)/Journal of Shenzhen University Science and Engineering, 31(6), 593-599. http://doi.org/10.3724/SP.J.1249.2014.06593

Loiseau, E., Junqua, G., Roux, P., \& Bellon-Maurel, V. (2012). Environmental assessment of a territory: An overview of existing tools and methods. Journal of Environmental Management, 112(Supplement $\quad$ C), 213-225. http://doi.org/https://doi.org/10.1016/j.jenvman.2012.07.024

Lundqvist, L. J. (2016). Planning for Climate Change Adaptation in a Multi-level Context: The Gothenburg Metropolitan Area. EUROPEAN PLANNING STUDIES, 24(1), 1-20. http://doi.org/10.1080/09654313.2015.1056774

Malekpour, S., Brown, R. R., \& de Haan, F. J. (2015). Strategic planning of urban infrastructure for environmental sustainability: Understanding the past to intervene for the future. Cities, 46, 67-75.

Martin, S. A. (2015). A framework to understand the relationship between social factors that reduce resilience in cities: Application to the City of Boston. International Journal of Disaster Risk Reduction, 12, 53-80. article. http://doi.org/10.1016/j.ijdrr.2014.12.001

Marull, J., Pino, J., Mallarach, J. M., \& Cordobilla, M. J. (2007). A Land Suitability Index for Strategic Environmental Assessment in metropolitan areas. Landscape and Urban Planning, 81(3), 200-212. http://doi.org/10.1016/j.landurbplan.2006.11.005

McCarthy, J.J., O.F. Canziani, N.A. Leary, D. J. D. and K. S., \& (eds), W. (2001). Climate change 2001: impacts, adaptation, and vulnerability. Cambridge University Press, Cambridge. 
McCormick, S. (2016). Assessing climate change vulnerability in urban America: stakeholder-driven approaches. CLIMATIC CHANGE, 138(3-4), 397-410. article. http://doi.org/10.1007/s10584-016-1757-3

Mohammad, K., \& Zahmatkesh, Z. (2017). Quantifying resilience and uncertainty in coastal flooding events: Framework for assessing urban vulnerability. Journal of Water Resources Planning and Management, 143(1). http://doi.org/10.1061/(ASCE)WR.1943-5452.0000724

Mokhberi, M. (2015). Vulnerability evaluation of the urban area using the H/V spectral ratio of microtremors. International Journal of Disaster Risk Reduction, 13, 369374. http://doi.org/10.1016/j.ijdrr.2015.06.012

Moradi, M., Delavar, M. R., Moshiri, B., \& Khamespanah, F. (2014). A NOVEL APPROACH TO SUPPORT MAJORITY VOTING IN SPATIAL GROUP MCDM USING DENSITY INDUCED OWA OPERATOR FOR SEISMIC VULNERABILITY ASSESSMENT. ISPRS - International Archives of the Photogrammetry, Remote Sensing and Spatial Information Sciences, XL2/W3(2W3), 209-214. http://doi.org/10.5194/isprsarchives-XL-2-W3-209-2014

Munda, G. (2004). Social multi-criteria evaluation: Methodological foundations and operational consequences. European Journal of Operational Research, 158(3), 662-677. http://doi.org/10.1016/S0377-2217(03)00369-2

Nahiduzzaman, K. M., Aldosary, A. S., \& Rahman, M. T. (2015). Flood induced vulnerability in strategic plan making process of Riyadh city. Habitat International, 49, 375-385. http://doi.org/10.1016/j.habitatint.2015.05.034

National Assessment Synthesis Team: 2001,Climate Change Impacts on the United States: The Potential Consequences of Climate Variability and Change, Cambridge University Press, Cambridge.

Novelli, V. I., D’Ayala, D., Makhloufi, N., Benouar, D., \& Zekagh, A. (2014). A procedure for the identification of the seismic vulnerability at territorial scale. Application to the Casbah of Algiers. Bulletin of Earthquake Engineering, 13(1), 177-202. http://doi.org/10.1007/s10518-014-9666-1

O'Faircheallaigh, C. (2010). Public participation and environmental impact assessment: Purposes, implications, and lessons for public policy making. Environmental Impact Assessment Review, 30(1), 19-27. http://doi.org/https://doi.org/10.1016/j.eiar.2009.05.001

Ouma, Y., \& Tateishi, R. (2014). Urban Flood Vulnerability and Risk Mapping Using Integrated Multi-Parametric AHP and GIS: Methodological Overview and Case 
Study Assessment. Water, 6(6), 1515-1545. http://doi.org/10.3390/w6061515

Pamungkas, A., Bekessy, S. A., \& Lane, R. (2014). Vulnerability Modelling to Improve Assessment Process on Community Vulnerability. Procedia Social and Behavioral Sciences, 135, 159-166. http://doi.org/10.1016/j.sbspro.2014.07.341

Penades-Pla, V., Garcia-Segura, T., Marti, J. V, \& Yepes, V. (2016). A Review of MultiCriteria Decision-Making Methods Applied to the Sustainable Bridge Design. SUSTAINABILITY, 8(12). http://doi.org/10.3390/su8121295

Torres-Machi, C., Pellicer, E., Yepes, V., \& Chamorro, A. (2017). Towards a sustainable optimization of pavement maintenance programs under budgetary restrictions. Journal of Cleaner Production, 148, 90-102. article. http://doi.org/http://doi.org/10.1016/j.jclepro.2017.01.100

Radmehr, A., \& Araghinejad, S. (2014). Developing Strategies for Urban Flood Management of Tehran City Using SMCDM and ANN. Journal of Computing in Civil Engineering, 28(6), 05014006. http://doi.org/10.1061/(ASCE)CP.19435487.0000360

Radmehr, A., \& Araghinejad, S. (2015). Flood Vulnerability Analysis by Fuzzy Spatial Multi Criteria Decision Making. Water Resources Management, 29(12), 44274445. http://doi.org/10.1007/s11269-015-1068-X

Remki, M., \& Benouar, D. (2014). Damage potential and vulnerability functions of strategic buildings in the city of Algiers. KSCE Journal of Civil Engineering, 18(6), 1726-1734. http://doi.org/10.1007/s12205-014-0184-0

Rigillo, M., \& Cervelli, E. (2014). Mapping Urban Vulnerability: the Case Study of Gran Santo Domingo, Dominican Republic. Advanced Engineering Forum, 11, 142-148. http://doi.org/10.4028/www.scientific.net/AEF.11.142

Romero Lankao, P., \& Qin, H. (2011b). Conceptualizing urban vulnerability to global climate and environmental change. Current Opinion in Environmental Sustainability, 3(3), 142-149. http://doi.org/10.1016/j.cosust.2010.12.016

Romero-Lankao, P., Hughes, S., Qin, H., Hardoy, J., Rosas-Huerta, A., Borquez, R., \& Lampis, A. (2014). Scale, urban risk and adaptation capacity in neighborhoods of Latin American cities. Habitat International, 42, 224-235. http://doi.org/10.1016/j.habitatint.2013.12.008

Rosenzweig, C., Solecki, W. D., Blake, R., Bowman, M., Faris, C., Gornitz, V., ... Zimmerman, R. (2011). Developing coastal adaptation to climate change in the New York City infrastructure-shed: Process, approach, tools, and strategies. Climatic Change, 106(1), 93-127. article. http://doi.org/10.1007/s10584-010-00028

Rufat, S. (2012). Spectroscopy of Urban Vulnerability. Annals of the Association of American Geographers, 103(3), $505-525$. 
http://doi.org/10.1080/00045608.2012.702485

Sabato, V., \& Mugavero, R. (2012). Application of a qualitative model for evaluation of expected risk in an urban crisis: Case study on rome. Defence $S$ and T Technical Bulletin, 5(1), 46-56.

Saha, M., \& Eckelman, M. J. (2014). Urban scale mapping of concrete degradation from projected climate change. Urban Climate, 9, 101-114. http://doi.org/10.1016/j.uclim.2014.07.007

Shach-Pinsly, D., \& Ganor, T. (2015). Security sensitivity index: Evaluating urban vulnerability. Proceedings of the Institution of Civil Engineers: Urban Design and Planning, 168(3), 115-128. Retrieved from

Shieh, E., Habibi, K., Torabi, K., \& E. Masoumi, H. (2014). Earthquake risk in urban street network: an example from region 6 of Tehran, Iran. International Journal of Disaster Resilience in the Built Environment, 5(4), 413-426. http://doi.org/10.1108/IJDRBE-04-2011-0017

Shiehbeiki, S., Abbaspour, M., Monavari, S. M., Arjmandi, R., \& Lahijanian, A. (2014). Public Participation Role in Sustainable Urban Management by Quantitative Strategic Planning Matrix (QSPM). International Journal of Environmental Research, 8(4), 1309-1314.

Shuang, Q., Zhang, M., \& Yuan, Y. (2014). Node vulnerability of water distribution networks under cascading failures. Reliability Engineering \& System Safety, 124, 132-141. http://doi.org/10.1016/j.ress.2013.12.002

Slootweg, R., \& Jones, M. (2011). Resilience thinking improves SEA: A discussion paper. Impact Assessment and Project Appraisal.

Smith, H., \& Jenkins, P. (2015). Trans-disciplinary research and strategic urban expansion planning in a context of weak institutional capacity: Case study of Huambo, Angola. Habitat International, 46, 244-251.

Solín, L. (2012). Spatial variability in the flood vulnerability of urban areas in the headwater basins of Slovakia. Journal of Flood Risk Management, 5(4), 303-320. http://doi.org/10.1111/j.1753-318X.2012.01153.x

Su, B., Huang, H., \& Zhang, N. (2015). Dynamic urban waterlogging risk assessment method based on scenario simulations. Qinghua Daxue Xuebao/Journal of Tsinghua University, 55(6), 684-690. Retrieved from

Sun, D., Zhao, Y., \& Lu, Q.-C. (2015). Vulnerability Analysis of Urban Rail Transit Networks: A Case Study of Shanghai, China. Sustainability, 7(6), 6919-6936. http://doi.org/10.3390/su7066919

Syed, A., \& Kumar Routray, J. (2014). Vulnerability assessment of earthquake prone communities in Baluchistan. International Journal of Disaster Resilience in the Built Environment, 5(2), 144-162. http://doi.org/10.1108/IJDRBE-12-2010-0053 
Takagi, H., Li, S., de Leon, M., Esteban, M., Mikami, T., Matsumaru, R., et al. (2016). Storm surge and evacuation in urban areas during the peak of a storm. Coastal Engineering, 108, 1-9. http://doi.org/10.1016/j.coastaleng.2015.11.002

Temes, R. R. (2014). Valoración de la vulnerabilidad integral en las áreas residenciales de Madrid. EURE (Santiago), 40(119), 119-149. http://doi.org/10.4067/S0250$\underline{71612014000100006}$

Tilio, L., Murgante, B., Di Trani, F., Vona, M., \& Masi, A. (2012). Mitigation of urban vulnerability through a spatial multicriteria approach. Disaster Advances, 5(3), $138-143$.

Tonmoy, F. N., El-Zein, A., \& Hinkel, J. (2014). Assessment of vulnerability to climate change using indicators: a meta-analysis of the literature. Wiley Interdisciplinary Reviews: Climate Change, 5(6), 775-792. http://doi.org/10.1002/wcc.314

Toubin, M., Laganier, R., Diab, Y., \& Serre, D. (2015). Improving the Conditions for Urban Resilience through Collaborative Learning of Parisian Urban Services. JOURNAL OF URBAN PLANNING AND DEVELOPMENT, 141(4). http://doi.org/10.1061/(ASCE)UP.1943-5444.0000229

Turner, B. L., Kasperson, R. E., Matson, P. A., McCarthy, J. J., Corell, R. W., Christensen, L., et al. (2003). A framework for vulnerability analysis in sustainability science. Proceedings of the National Academy of Sciences of the United States of America, 100(14), 8074-8079. http://doi.org/10.1073/pnas.1231335100

Uejio, C. K., Wilhelmi, O. V, Golden, J. S., Mills, D. M., Gulino, S. P., \& Samenow, J. P. (2011). Intra-urban societal vulnerability to extreme heat: the role of heat exposure and the built environment, socioeconomics, and neighborhood stability. Health \& Place, 17(2), 498-507. http://doi.org/10.1016/j.healthplace.2010.12.005

Wiechmann, T. (2008). Errors Expected : Aligning Urban Strategy with Demographic Uncertainty in Shrinking Cities. International Planning Studies, 13(4), 431-446. http://doi.org/10.1080/13563470802519097

Wolf, S., Hinkel, J., Hallier, M., Bisaro, A., Lincke, D., Ionescu, C., \& Klein, R. J. T. (2013). Clarifying vulnerability definitions and assessments using formalisation. International Journal of Climate Change Strategies and Management, 5(1), 54-70. http://doi.org/10.1108/17568691311299363

Yepes, V., García-Segura, T., \& Moreno-Jiménez, J. M. (2015). A cognitive approach for the multi-objective optimization of RC structural problems. Archives of Civil and Mechanical Engineering, 15(4), 1024-1036. http://doi.org/10.1016/j.acme.2015.05.001 
Zamarrón-Mieza, I., Yepes, V., \& Moreno-Jiménez, J. M. (2017). A systematic review of application of multi-criteria decision analysis for aging-dam management.

Journal of Cleaner Production, 147, 217-230. article.

http://doi.org/http://doi.org/10.1016/j.jclepro.2017.01.092

Zanetti, V. B., Junior, W. C. S., \& De Freitas, D. M. (2016). A climate change vulnerability index and case study in a Brazilian Coastal City. Sustainability (Switzerland), 8(8). JOUR. http://doi.org/10.3390/su8080811

Zhang, M. Y., Yuan, Y. B., \& Zhou, J. (2010). A new method of urban natural disaster risk analysis. Dalian Ligong Daxue Xuebao/Journal of Dalian University of Technology, 50(5), 706-711. 


\section{Acknowledgments}

The authors acknowledge the financial support of the Spanish Ministry of Economy and

Competitiveness, along with FEDER funding (BRIDLIFE Project: BIA2014-56574-R).

\section{List of Tables}

Table 1. Developmental stages and their characteristic evolution.

\begin{tabular}{|c|c|c|c|c|c|c|}
\hline & \multicolumn{2}{|l|}{ Domain: } & \multicolumn{3}{|c|}{ Stages: } & \multirow{2}{*}{$\begin{array}{c}\text { Reference: } \\
\begin{array}{c}\text { Malepour et } \\
\text { al., } 2015\end{array}\end{array}$} \\
\hline \multirow{4}{*}{$\begin{array}{c}\text { Developmental } \\
\text { stages }\end{array}$} & \multirow{2}{*}{\multicolumn{2}{|c|}{ Urban strategic planning }} & Incremental & Managerial & Discursive & \\
\hline & & & incremental & $\begin{array}{l}\text { Modeling- } \\
\text { managerial }\end{array}$ & discursive & $\begin{array}{l}\text { Dominguez } \\
\text { et al., } 2011\end{array}$ \\
\hline & \multirow{2}{*}{\multicolumn{2}{|c|}{ Vulnerability assessment }} & $\begin{array}{l}\text { impact } \\
\text { assessment } \\
\text { (Fussel, } \\
\text { 2003) }\end{array}$ & $\begin{array}{l}\text { vulnerability } \\
\text { assessment } \\
\text { (National } \\
\text { Assessment } \\
\text { Synthesis } \\
\text { Team, 2001) }\end{array}$ & $\begin{array}{l}\text { adaptation policy } \\
\text { (Harrison, 2015) }\end{array}$ & $\begin{array}{l}\text { Fussell et } \\
\text { al., } 2006\end{array}$ \\
\hline & & & preparation & ada & ptation & Adger, 2006 \\
\hline \multirow{3}{*}{$\begin{array}{l}\text { Characteristic } \\
\text { evolution }\end{array}$} & \multirow{3}{*}{$\begin{array}{c}\text { Urban } \\
\text { strategic } \\
\text { planning / } \\
\text { vulnerability } \\
\text { assessment }\end{array}$} & $\begin{array}{c}\text { Consideration } \\
\text { of adaptation }\end{array}$ & $\begin{array}{c}\text { control } \\
\text { status quo / } \\
\text { little }\end{array}$ & $\begin{array}{c}\text { strategic } \\
\text { (present and } \\
\text { long range) } \\
\text { planning/ } \\
\text { mid-to long- } \\
\text { term } \\
\text { optimization } \\
\text { of status quo / } \\
\text { partial-full }\end{array}$ & $\begin{array}{c}\text { strategic (present } \\
\text { and long range) } \\
\text { planning / short-to } \\
\text { long-term }\end{array}$ & \multirow{3}{*}{$\begin{array}{c}\text { Malepour et } \\
\text { al., 2015 / } \\
\text { Fussell et } \\
\text { al., } 2006\end{array}$} \\
\hline & & $\begin{array}{l}\text { Consideration } \\
\text { of uncertainty }\end{array}$ & $\begin{array}{l}\text { future } \\
\text { forecast / } \\
\text { little }\end{array}$ & $\begin{array}{l}\text { uncertainty } \\
\text { management } \\
\text { through } \\
\text { scenario } \\
\text { planning / } \\
\text { partial } \\
\text { public-private, } \\
\text { stakeholders } \\
\text { invonvement / } \\
\text { medium }\end{array}$ & $\begin{array}{l}\text { umpredictability } \\
\text { is accepted, } \\
\text { uncertainty is } \\
\text { explored / } \\
\text { extensive } \\
\text { citizens' } \\
\text { involvement / } \\
\text { high }\end{array}$ & \\
\hline & & $\begin{array}{l}\text { Analytical } \\
\text { approach } \\
\text { Integration- } \\
\text { complexity } \\
\text { asumption }\end{array}$ & $\begin{array}{c}\text { rational / } \\
\text { positive } \\
\text { from linear } \\
\text { to non-linear } \\
\text { complex } \\
\text { patterns / } \\
\text { low }\end{array}$ & $\begin{array}{l}\text { cognitive / } \\
\text { mainly } \\
\text { positive } \\
\text { complexity } \\
\text { theory, } \\
\text { predict-and- } \\
\text { act / medium- } \\
\text { high }\end{array}$ & $\begin{array}{l}\text { Cognitive and } \\
\text { post-normal / } \\
\text { normative } \\
\text { adaptive } \\
\text { approaches / high }\end{array}$ & \\
\hline
\end{tabular}


Table 2. Research requirements of USP and UVA.

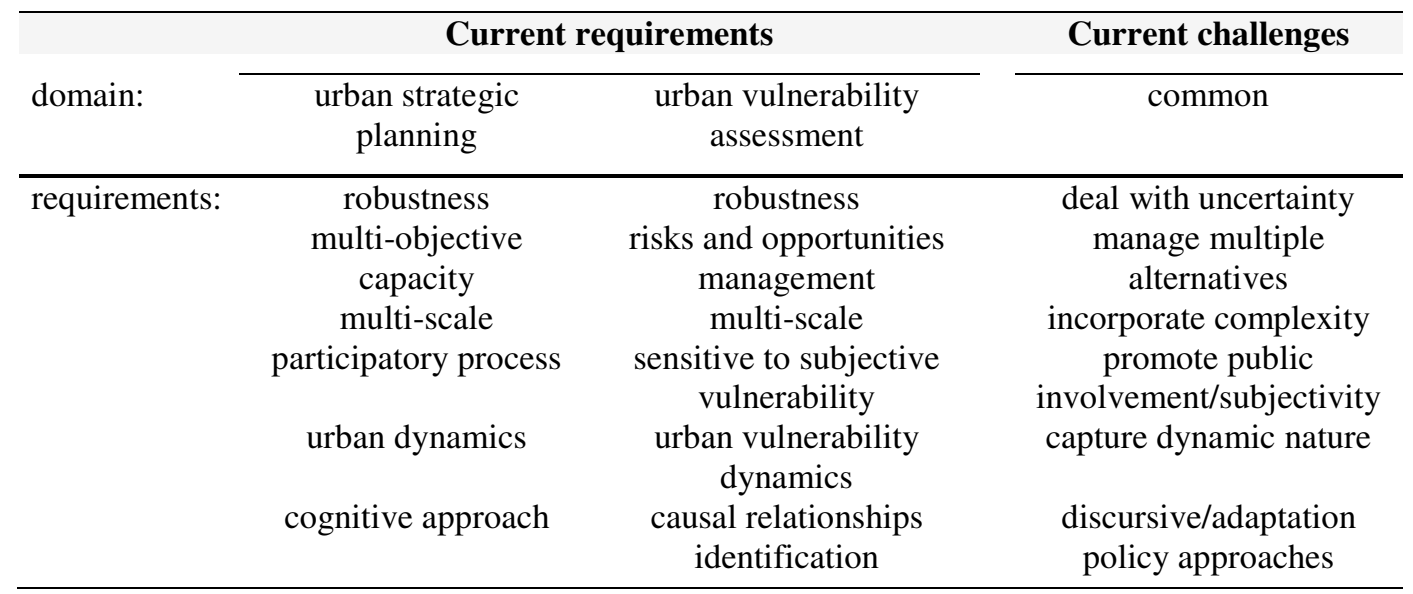


Table 3. Description of urban vulnerability assessment methods.

\begin{tabular}{|c|c|c|c|c|c|c|c|c|c|c|}
\hline \multicolumn{11}{|c|}{$\begin{array}{l}\text { Mean and Std refers to the distribution of Studies accord } \\
\text { Reference values for means are provided at the bottom }\end{array}$} \\
\hline \multirow{2}{*}{ Atributes } & \multicolumn{2}{|c|}{ Studies } & \multicolumn{2}{|c|}{ Year $(*)$} & \multicolumn{2}{|c|}{ Approach (**) } & \multicolumn{2}{|c|}{ Evol. stage $(* * *)$} & \multicolumn{2}{|c|}{ Simultaneous req } \\
\hline & $\begin{array}{c}\text { Coun } \\
t\end{array}$ & $\%$ & Mean & $\begin{array}{c}\text { St } \\
\text { Dev }\end{array}$ & Mean & $\begin{array}{c}\text { St } \\
\text { Dev }\end{array}$ & Mean & St Dev & Mean & St Dev \\
\hline \multicolumn{11}{|l|}{ approach: } \\
\hline $\begin{array}{l}\text { (1) } \\
\text { biophysical }\end{array}$ & 22 & 34 & 41,620 & 476 & & & 1.833 & 0.541 & 0.777 & 1.000 \\
\hline $\begin{array}{l}\text { (2) } \\
\text { comprehensiv } \\
\mathrm{e}\end{array}$ & 23 & 35 & 41,799 & 621 & & & 2.13 & 0.548 & 0.826 & 0.936 \\
\hline (3) social & 20 & 31 & 41,559 & 581 & & & 1.778 & 0.427 & 0.667 & 0.618 \\
\hline \multicolumn{11}{|l|}{ Evol. stage: } \\
\hline impact & 10 & 15 & & & & & & & 0.7 & 0.675 \\
\hline vulnerability & 48 & 74 & & & & & & & 0.651 & 0.814 \\
\hline adaptation & 7 & 11 & & & & & & & 1.667 & 1.003 \\
\hline \multicolumn{11}{|l|}{ Stimuli: } \\
\hline \multicolumn{11}{|l|}{$1^{\text {st }}$ Order: } \\
\hline natural & 12 & 12 & 41,773 & 678 & 2.182 & 0.751 & & & & \\
\hline seismic & 18 & 34 & 41,526 & 511 & 1.875 & 0.885 & & & & \\
\hline water flooding & 20 & 24 & 41,782 & 640 & 2 & 0.686 & & & & \\
\hline social & 9 & 18 & 41,594 & 362 & 2 & 0.756 & & & & \\
\hline \multicolumn{11}{|l|}{$2^{\text {nd }}$ Order: } \\
\hline underg. Infras & 3 & 6 & 41,518 & 843 & 2.333 & 1.155 & & & & \\
\hline surf. Infras & 3 & 6 & 41,762 & 210 & 1.677 & 1.155 & & & & \\
\hline \multicolumn{11}{|l|}{ Simultaneous req... } \\
\hline 0 & 30 & 47 & & & & & 1.893 & 0.416 & & \\
\hline 1 & 22 & 34 & & & & & 1.8 & 0.523 & & \\
\hline 2 & 9 & 14 & & & & & 2.25 & 0.707 & & \\
\hline 3 & 3 & 5 & & & & & 2.333 & 0.577 & & \\
\hline
\end{tabular}

Note: Reference values closer to aspect means indicates the category to which the latter is more prone:

$(*)$ reference values corresponding to each year: $2010=40,361 ; 2011=40,762 ; 2012=41,091 ; 2013=41,457 ; 2014=41,882 ; 2015=42,187$;

(**) reference values corresponding to each approach: biophysical $=1$; comprehensive $=2$; social $=3$

(***) reference values corresponding to each evol. stage: impact=1; vulnerability $=2$; adaptation $=3$.

(1) Biophysical references: Zhang et al, (2010); Chiauzzi et al., (2011); Albuquerque et al., (2013); Bristow, E. C. \& Brumbelow, K. (2013); Aina, Y . A., \& Aleem, K. F. (2014); Duggal, B. (2014); Kaji et al., (2014); Moradi et a., (2014); Novelli et al., (2014); Radmehr, A., \& Araghinejad, S. (2014); Shieh et al., (2014); Ouma, Y., \& Tateishi, R. (2014); Yuan et al., (2014); Christodoulou, S. E., \& Fragiadakis, M. (2015); Deng et al., (2015); Guardiola-Villora et al., (2015); Kirshen et al., (2015);Mokhberi, M. (2015); Saha, M., \& Eckelman, M. J. (2014); Sun et al., (2015); Fischer et al., (2016); Rosenzweiget al., (2011);

(2) Comprehensive references: Bendaoui et al., (2010); An et al., (2011); Cagno et ,al., (2011); Sabato, V., \& Mugavero, R. (2012); Solín, L. (2012); Ferreira et al.., (2013); Bosiljkov et al.., (2014); Cai et al., (2014); Heaton et al., (2014); Kimani-Murage et al., (2014); Remki, M., \& Benouar, D. (2014); Shuang et al., (2014); Syed et al., (2014); Giardina et al., (2015); Radmehr, A., \& Araghinejad, S. (2015); Shach-Pinsly, D., \& Ganor, T. (2015); Su et al., (2015); Ding et al., (2016); Shenet al., (2016); Codjoe \& Afuduo, (2015); Mohammad \& Zahmatkesh, (2017); Kriščiukaitiene et al., (2015); Armaş et al.,. (2016); Zanetti et al., (2016); Karagiorgos et al., (2016); Fernandez et al., (2016).

(3) Social references: Esmaeili, V. (2014); Carreño et al., (2011); Uejio et al., (2011); Rufat, S. (2012); Tilio et a., (2012); Chen et al., (2013); Ahmad, S. S., \& Simonovic, S. P. (2013); Alguacil Gómez et al., (2014); Temes, R. R. (2014); Fang \& Wang, (2015); Lemonsu et al., (2015); Kotzee, I., \& Reyers, B. (2016a); Takagi et al., (2016); Bradfordet al., (2015); Kumar et al., (2016); Martin, (2015); Koks et al., (2015); 
Table 4. Urban vulnerability assessment research requirement types.

\begin{tabular}{lccc}
\hline & & \multicolumn{2}{c}{$\%$} \\
\cline { 3 - 4 } & count & $\begin{array}{c}\text { Absolute } \\
(1)^{*}\end{array}$ & $\begin{array}{c}\text { Relative } \\
(2)^{*}\end{array}$ \\
\hline (1) assessment methods fully reviewed: & 65 & 100 & \\
(2) assessment undertaking requirements & 35 & 54 & 100 \\
\hline robustness-uncertainty & 17 & 26 & 49 \\
participatory-subjectivity & 11 & 17 & 31 \\
multi scale-complexity & 3 & 5 & 9 \\
dynamic nature & 4 & 6 & 11 \\
multi objective-strategic capacity & 3 & 5 & 9 \\
cognitive-cause effect & 13 & 20 & 37 \\
\hline * Note: Absolute (1) and Relative (2) are percentages respectively referring to all UVAs \\
reviewed, and to exclusively those also undertaking requirements \\
\hline
\end{tabular}

Table 5. Assessments per number of simultaneously undertaken requirements.

\begin{tabular}{ccc} 
number & count & $\%$ \\
\hline 0 & 30 & 46 \\
1 & 22 & 34 \\
2 & 10 & 15 \\
3 & 3 & 5 \\
\hline
\end{tabular}


Table 6. Description of research requirements undertaken by urban vulnerability assessment methods.

\begin{tabular}{|c|c|c|c|c|c|c|c|}
\hline \multirow[b]{2}{*}{ aspects } & \multicolumn{7}{|c|}{ research requirements } \\
\hline & $\begin{array}{c}\text { Robustne } \\
\text { ss/uncert } \\
\text { ainty }\end{array}$ & $\begin{array}{c}\text { Participato } \\
\text { ry/subjecti } \\
\text { vity }\end{array}$ & $\begin{array}{l}\text { Multi- } \\
\text { scale/co } \\
\text { mplexit } \\
\text { y }\end{array}$ & $\begin{array}{l}\text { dynami } \\
\text { c nature }\end{array}$ & $\begin{array}{c}\text { Multi- } \\
\text { objective- } \\
\text { strategic/ } \\
\text { capacity }\end{array}$ & $\begin{array}{c}\text { Cognit } \\
\text { ive/cau } \\
\text { se- } \\
\text { effect }\end{array}$ & total \\
\hline Count & 17 & 11 & 3 & 4 & 3 & 13 & 51 \\
\hline (1) $\%$ & 33 & 22 & 6 & 8 & 6 & 25 & 100 \\
\hline $\begin{array}{l}\text { (2) Mean along } \\
\text { Year }(*)\end{array}$ & 41,744 & 41,905 & 42,127 & 41,457 & 41,640 & 41,752 & \\
\hline (3) Std along Year & 631 & 567 & 421 & 966 & 365 & 524 & \\
\hline $\begin{array}{l}\text { (4) Trend = } \\
(1) \times(2) \times(3)\end{array}$ & $8.6 \mathrm{E} 6$ & $5.2 \mathrm{E} 6$ & $1.0 € 6$ & $3.2 \mathrm{E} 6$ & $0.1 \mathrm{E} 6$ & $5.4 \mathrm{E} 6$ & \\
\hline
\end{tabular}

Year:

\begin{tabular}{cccccccc}
2010 & 1 & 0 & 0 & 1 & 0 & 0 & 2 \\
2011 & 2 & 1 & 0 & 0 & 0 & 1 & 2 \\
2012 & 0 & 0 & 0 & 0 & 0 & 0 & 0 \\
2013 & 2 & 0 & 0 & 1 & 1 & 2 & 6 \\
2014 & 3 & 4 & 1 & 0 & 1 & 4 & 11 \\
2015 & 5 & 1 & 0 & 1 & 0 & 3 & \\
2016 & 4 & 5 & 2 & 1 & 1 & 3 & 11 \\
\hline
\end{tabular}

\begin{tabular}{|c|c|c|c|c|c|c|c|}
\hline \multicolumn{8}{|l|}{ Approach: } \\
\hline biophysical & 10 & 3 & 1 & 1 & 2 & 3 & 20 \\
\hline $\begin{array}{l}\text { comprehensi } \\
\text { ve }\end{array}$ & 4 & 5 & 1 & 2 & 1 & 6 & 19 \\
\hline social & 3 & 3 & 1 & 1 & 0 & 4 & 12 \\
\hline
\end{tabular}

Evol. Stage:

\begin{tabular}{llllllll} 
impact & 4 & 2 & 1 & 0 & 0 & 1 & 8 \\
vulnerability & 9 & 7 & 2 & 3 & 2 & 9 & 32 \\
adaptation & 4 & 2 & 0 & 1 & 1 & 3 & 11 \\
\hline
\end{tabular}

Stimuli:

$\begin{array}{llllllll}\text { natural } & 5 & 3 & 1 & 1 & 0 & 2 & 12 \\ \text { generic } & 3 & 3 & 1 & 0 & 2 & 5 & 14 \\ \text { seismic } & 6 & 3 & 1 & 3 & 1 & 3 & 17 \\ \text { water } & 0 & 2 & 0 & 0 & 0 & 1 & 3 \\ \text { flooding } & 1 & 0 & 0 & 0 & 0 & 1 & 2 \\ \text { social } & 2 & 0 & 0 & 0 & 0 & 1 & 3 \\ \text { underg. } & \text { Infras } & & \end{array}$

Simultaneous req.:

$\begin{array}{lrrrrrrr}1 & 7 & 5 & 1 & 2 & 1 & 6 & 22 \\ 2 & 7 & 4 & 1 & 2 & 1 & 5 & 20 \\ 3 & 3 & 2 & 1 & 0 & 1 & 2 & 9 \\ \text { all } & 17 & 11 & 3 & 4 & 3 & 13 & 51\end{array}$


Table 7. Studies dealing with uncertainty.

\begin{tabular}{|c|c|c|c|c|c|c|c|}
\hline \multirow[b]{3}{*}{ model } & \multicolumn{4}{|c|}{ uncertainty approaches } & \multirow{2}{*}{\multicolumn{2}{|c|}{ total }} & \multirow[b]{3}{*}{ references } \\
\hline & incremental & & managerial & discursive & & & \\
\hline & no scenario & no scenario & no scenario & scenario & count & $\%$ & \\
\hline simulation & 0 & 5 & 1 & 4 & 10 & 59 & $\begin{array}{c}\text { Kaji et al., } \\
2014 ; \\
\text { Kirshen et } \\
\text { al., 2015; } \\
\text { Takagi et } \\
\text { al., 2016; } \\
\text { Bristow \& } \\
\text { Brumbelow, } \\
\text { 2013; } \\
\text { Lemonsu et } \\
\text { al., 2015; } \\
\text { Aina \& } \\
\text { Aleem, } \\
\text { 2014; } \\
\text { Giardina et } \\
\text { al., 2015. }\end{array}$ \\
\hline $\begin{array}{l}\text { complex } \\
\text { network/cascade } \\
\text { failure }\end{array}$ & 0 & 0 & 2 & 0 & 2 & 12 & $\begin{array}{l}\text { Yuan et al., } \\
\text { 2014; Sun } \\
\text { et al., } 2015\end{array}$ \\
\hline fuzzy & 0 & 1 & 0 & 0 & 1 & 6 & $\begin{array}{c}\text { Ahmad \& } \\
\text { Simonovic, } \\
2013 \\
\end{array}$ \\
\hline other & 4 & 0 & 0 & 0 & 4 & 24 & $\begin{array}{c}\text { Chiauzzi et } \\
\text { al., } \\
\text { 2011;Zhang } \\
\text { et al., } 2013\end{array}$ \\
\hline total count & 4 & 6 & 3 & 4 & 17 & 100 & \\
\hline total $\%$ & 24 & 35 & 18 & 24 & & & \\
\hline
\end{tabular}

Table 8. Evaluation of the advancement made on urban vulnerability assessment methods.

Table 8. Evaluation of the advancement made on urban vulnerability assessment methods

\begin{tabular}{|c|c|c|c|c|c|}
\hline \multirow[b]{2}{*}{ requirements } & \multicolumn{2}{|c|}{ Quantitative (1) } & \multicolumn{2}{|c|}{ Qualitative (2) } & \multirow{2}{*}{$\begin{array}{l}\text { Overall (2) } \\
\text { advancement }\end{array}$} \\
\hline & $\begin{array}{c}\% \\
\text { research } \\
\text { effort } \\
\end{array}$ & $\begin{array}{l}\text { present } \\
\text { trend }\end{array}$ & $\begin{array}{l}\text { proximity to } \\
\text { strategic } \\
\text { planning } \\
\end{array}$ & $\begin{array}{l}\text { multiple } \\
\text { requirements }\end{array}$ & \\
\hline $\begin{array}{l}\text { robustness- } \\
\text { uncertainty }\end{array}$ & good & good & good & good & significant \\
\hline $\begin{array}{l}\text { participatory- } \\
\text { subjectivity }\end{array}$ & medium & medium & medium & low & significant \\
\hline $\begin{array}{l}\text { multiscale- } \\
\text { complexity }\end{array}$ & low & low & low & low & almost null \\
\hline $\begin{array}{l}\text { urban } \\
\text { dynamics } \\
\text { multi }\end{array}$ & medium & medium & medium & medium & almost null \\
\hline $\begin{array}{l}\text { objective- } \\
\text { strategic }\end{array}$ & low & low & medium & good & limited \\
\hline $\begin{array}{l}\text { cognitive- } \\
\text { cause effect }\end{array}$ & good & medium & medium & good & significant \\
\hline
\end{tabular}

Note: Criteria for clustering into classes good, medium or low:

(1): \% of UVA methods and value of Trend in Table 6

(2): Assessment in section 6, Analytical Framework.

\section{List of Figures}


Fig. 1. Influence of approach on evolutive stage.

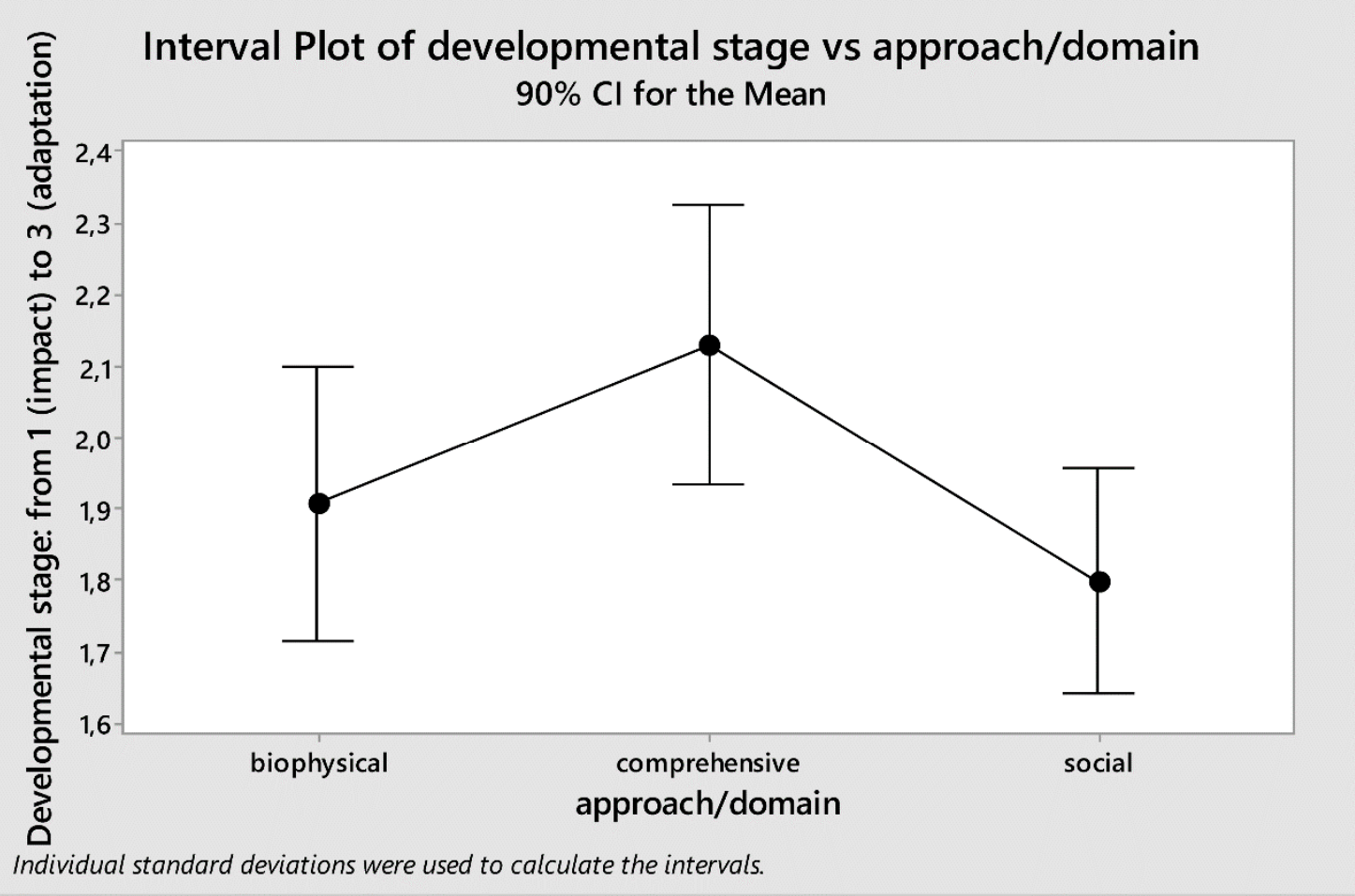

Fig. 2. Studies per evolutive stage and year.

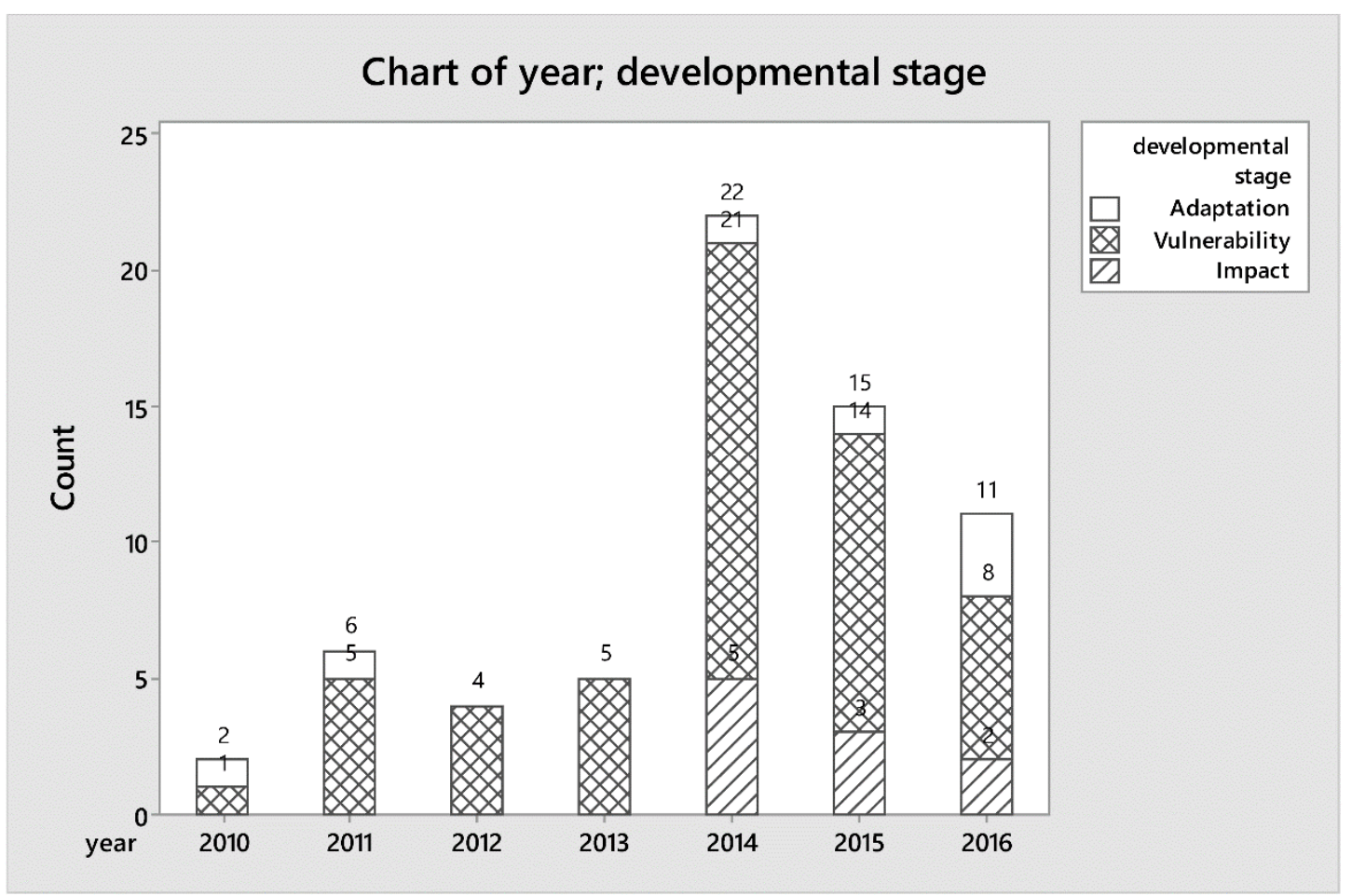

Fig. 3. Cluster result. 


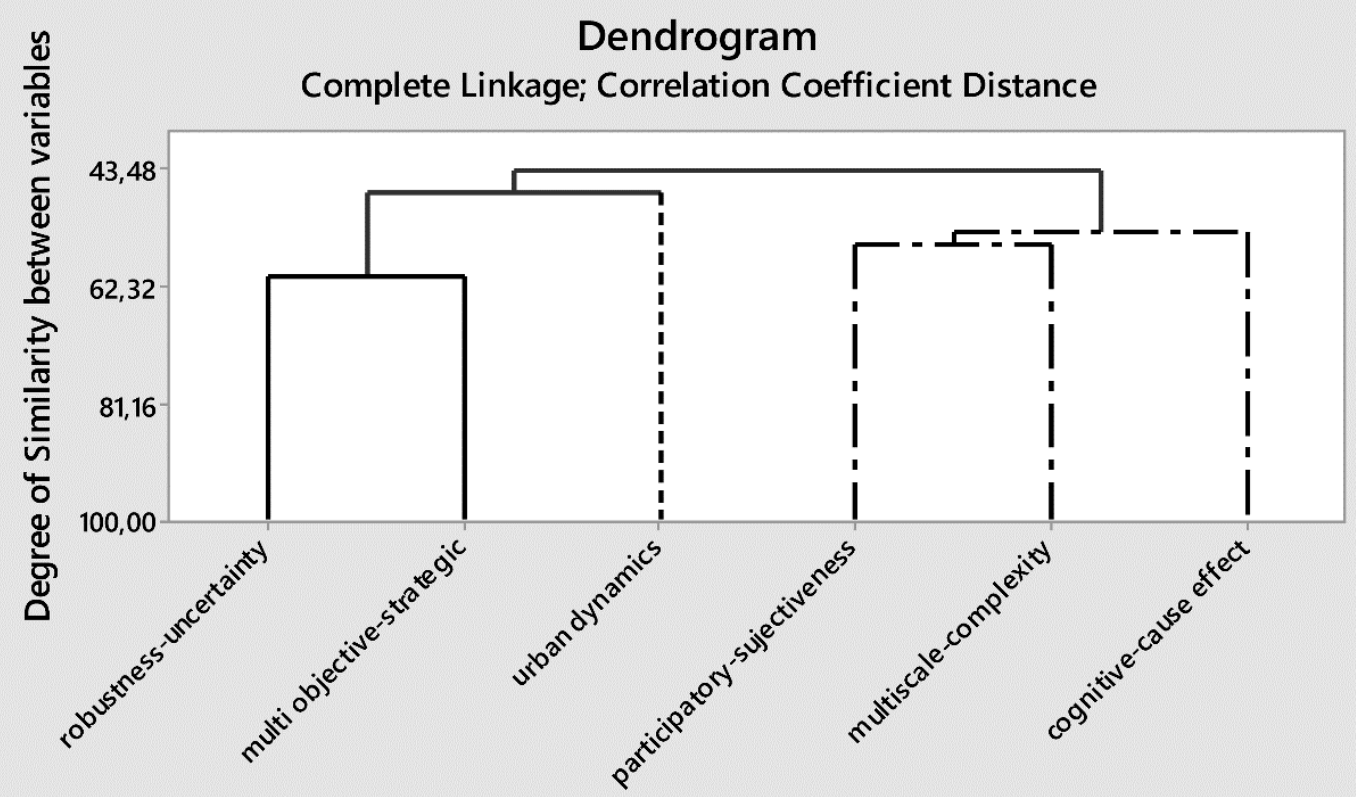

Variables

Variables with the same type of line are a cluster 